\title{
A Precipitation-Based Index for Tropical Intraseasonal Oscillations
}

\author{
SHUGUANG WANG \\ School of Atmospheric Sciences, Nanjing University, Nanjing, China, and Department of Applied Physics and \\ Applied Mathematics, Columbia University, New York City, New York
}

(Manuscript received 8 January 2019, in final form 11 August 2019)

\begin{abstract}
Characteristic patterns of precipitation-associated tropical intraseasonal oscillations, including the Madden-Julian oscillation (MJO) and boreal summer intraseasonal oscillation (BSISO), are identified using local empirical orthogonal function (EOF) analysis of the Tropical Rainfall Measuring Mission (TRMM) precipitation data as a function of the day of the year. The explained variances of the EOF analysis show two peaks across the year: one in the middle of the boreal winter corresponding to the MJO and the other in the middle of summer corresponding to the BSISO. Comparing the fractional variance indicates that the BSISO is more coherent than the MJO during the TRMM period. Similar EOF analyses with the outgoing longwave radiation (OLR) confirm this result and indicate that the BSISO is less coherent before the TRMM era (197998). In contrast, the MJO exhibits much less decadal variability. A precipitation-based index for tropical intraseasonal oscillation (PII) is derived by projecting bandpass-filtered precipitation anomalies to the two leading EOFs as a function of day of the year. A real-time version that approximates the PII is further developed using precipitation anomalies without any bandpass filtering. It is further shown that this real-time PII index may be used to diagnose precipitation in the subseasonal forecasts.
\end{abstract}

\section{Introduction}

Tropical intraseasonal oscillations (ISO), including the Madden-Julian oscillation (MJO; Madden and Julian 1971, 1972; Xie et al. 1963; Li et al. 2018) and boreal summer intraseasonal oscillation (BSISO; e.g., Yasunari 1979; Krishnamurti and Subrahmanyam 1982), consist of complex patterns of circulation, clouds, and rain. They are the primary modes of tropical weather at intraseasonal time scales and exerting far-reaching influence on global weather and climate.

For many practical applications, it is important to extract the MJO/BSISO signals from gridded data, for example, reanalysis products and/or interpolated observations. An index is a fundamental tool for quantitative expression of tropical ISOs. It serves to express ISO activity in simple numbers that efficiently abstracts spatial and temporal patterns and variations. Indexing $\mathrm{MJO} / \mathrm{BSISO}$ makes it feasible to quantify the amplitude and locations of the ISOs in observations and forecasts, which is important for the proper physical interpretation of MJO/BSISO life cycles. Indexing the ISO also allows study of their global impact. Many authors have found

Corresponding author: Shuguang Wang, wangsg@outlook.com that it is informative to index MJO based on bandpassfiltered variables (e.g., Hendon and Salby 1994; Maloney and Hartmann 1998; Ding et al. 2010). However, a limitation of this approach at that time is that it was not clear how one could use the index from bandpassfiltered data to track ISO in real time because data in the future are required but such data are unavailable for bandpass filtering in such circumstances. One major milestone in addressing this issue was the development of the Real-Time Multivariate MJO (RMM) index (Wheeler and Hendon 2004), which enabled real-time monitoring and forecasting of the MJO. Despite its major advantages, subsequent careful examination of the RMM revealed some limitations, for example, mixing MJO with other tropical wave signals, for example, Kelvin and/or Rossby waves (Roundy et al. 2009), and underrepresentation of convection (Straub 2013; Ventrice et al. 2013; Liu et al. 2016).

The bimodal ISO index developed by Kikuchi et al. (2012) and the outgoing longwave radiation (OLR)based MJO index (OMI) by Kiladis et al. (2014, hereafter referred to as K14) were developed to address this deficiency in RMM. Both are capable of tracking tropical convection associated with MJO based on 
OLR, which is a measure of cloudiness and has often been used as a surrogate for convection. Because OLR is directly measured by satellites at the global scale, it is considered highly reliable and perhaps the most accurate long-term climate record of tropical convection. A key distinction between RMM and OMI is that RMM applies latitudinal averages and it ignores the meridional structure of the MJO, while OMI includes meridional structures near the equator. The inclusion of meridional structures likely helps OMI better differentiate ISO from Kelvin waves, which are usually symmetrical with respect to each sides of equator. While OMI was designed to track the MJO, Wang et al. (2018) further showed that OMI is capable of tracking BSISO and, therefore, OMI offers a unified treatment of the MJO and BSISO, which is similar to the bimodal treatment of ISO in Kikuchi et al. (2012).

One very useful application of OMI is that it is suitable for subseasonal forecasts (Wang et al. 2019). There are several important differences between RMM and OMI besides the variables used. The first is that the two methods follow different approaches in constructing a real-time version index: OMI is based on the empirical orthogonal function (EOF) analysis of bandpass-filtered data and projecting real-timefiltered OLR onto these EOFs further removes noise, while RMM seeks to identify EOFs from anomalies computed using a window-processed technique. Both approaches provide a reasonable approximation of MJO in real time. Nevertheless, OMI offers a quantitative measure of this degree of approximation; that is, the correlation between real-time and filter-based index is $\sim 0.9$, while RMM provides no such measure. Despite its advantages, one limitation of the OMI is that it is not straightforward to relate OLR at the top of the atmosphere to precipitation at the surface.

Arguably, the most impactful aspect of the tropical intraseasonal oscillation is that it brings a significant amount of rain to the surface at low latitudes. Diabatic heating associated with precipitating processes during microphysical phase transformation generates Rossby waves. Propagation of these Rossby waves further influences mid- and high-latitude weather. Quantitatively characterizing, understanding, and predicting rainfall associated with ISO is of significant interest in a wide range of applications. Nevertheless, measuring precipitation associated with ISO remains a significant challenge. Several authors have begun to address this issue via Lagrangian feature tracking of precipitation during the MJO events (Kerns and Chen 2016; Zhang and Ling 2017). However, there is no quantitative forecast of $\mathrm{MJO} / \mathrm{BSISO}$ rainfall in operation to date.
The goal of this study is to fill this knowledge gap. We develop a simple index to measure MJO/BSISO daily precipitation based on the EOF analysis. This index identifies MJO/BSISO temporal and spatial patterns that are graphically interpretable. Our approach broadly follows K14 for cloudiness, and we improve upon K14 in two important aspects: improving consistency and reducing noise.

The rest of this article is organized in the following sections. Section 2 introduces the data, as well as the data preparation for precipitation anomalies, and describes the local EOF method. Section 3 contains results from the EOF analysis and discusses some basic properties of the precipitation index derived from the EOF analysis and its application to subseasonal forecasts. Section 4 summarizes this study.

\section{Data and methodology}

\section{a. TRMM precipitation and preprocessing}

We use the high-quality (HQ) microwave estimate of precipitation data from the Tropical Rainfall Measuring Mission (TRMM), version 3B42 7A, product (Huffman et al. 2007; Huffman and Bolvin 2013) for the analysis. The TRMM 3B42 HQ precipitation data are available from 1998 to the present. It is a gridded dataset with a horizontal resolution of $0.25^{\circ}$. We bin this data into $2.5^{\circ}$ resolution in standard longitude and latitude coordinates $\left(0^{\circ}, 2.5^{\circ}, 5^{\circ}, \ldots, 357.5^{\circ} \mathrm{E} ; \ldots,-5^{\circ} \mathrm{N},-2.5^{\circ} \mathrm{N}, 0^{\circ}\right.$, $\left.2.5^{\circ} \mathrm{N}, 5^{\circ} \mathrm{N}, \ldots\right)$. The daily average is obtained by binning the 3-hourly data. The $2.5^{\circ} \mathrm{HQ}$ data before 2015 (when TRMM was decommissioned) are used for the EOF analysis described below. For comparison, we also use the NOAA interpolated daily $2.5^{\circ}$-resolution OLR dataset (Liebmann and Smith 1996) from 1979 to 2017.

We perform EOF analysis on intraseasonal anomalies of precipitation and OLR. Similar to the computation of the OLR anomalies in K14, the following three steps are used to compute the precipitation and OLR anomalies from the $2.5^{\circ}$ daily TRMM-HQ precipitation prior to the EOF analysis. 1) Remove the climatology and the first three harmonics to obtain the daily precipitation anomalies. 2) Apply a 20-96-day bandpass filter to precipitation anomalies from step 1 with a 139-weight nonrecursive Lanczos filter. The filtfilt operation, a function in Python and MATLAB, is used to ensure zero phase shift. 3) Remove the mean and westward propagation components (keeping wavenumbers from 1 to 72) by transforming the data into the wavenumberfrequency space, setting the corresponding Fourier coefficients to 0 , and transforming back to the physical space. This last step is referred to as the eastward filter. Steps 1 and 2 are applied to data at each grid point; that 
is, these operations are independent of latitude and longitude. Step 3 is applied to data at each latitude circle. For the purpose of extracting EOFs, step 1 is not essential because time filtering in step 2 already removes low-frequency components. In fact, the EOF patterns remain nearly the same even if step 1 is skipped. It is nevertheless useful for making the real-time index, as discussed in section 3c.

\section{b. Local EOF analysis}

Our approach of using an EOF analysis of precipitation broadly follows that of K14 for OLR. The resultant EOFs are functions of the day of the year (DOY). As they are local in DOY (but covering the global equatorial regions in space), we refer to this as "local EOF analysis" to distinguish itself from conventional EOF analysis. We improve upon K14 in two aspects: noise reduction and improving consistency for interpretability. We apply the super-Gaussian function for noise reduction and apply rotation to the leading EOFs to make them more interpretable. We discuss the former in this section and the rotation operation in a later section.

The local EOF analysis requires appropriate selection of neighboring daily data centering on the current DOY. For this, we apply a super-Gaussian function for each DOY, which is written as

$$
\hat{F}(t, T)=F(t) \exp \left[-\left(\frac{t-T}{W}\right)^{4}\right],
$$

where $F$ is the gridded time series data (bandpass-filtered OLR or precipitation in this study, dependence on space is ignored for brevity); $\hat{F}(t, T)$ is the windowprocessed data as the input to the EOF analysis; $T$ denotes DOY, ranging from 0 to 364; and $W$ represents the half-width and indicates the rate of decay to zero. The super-Gaussian window is used based on our intuition that the time series data away from current DOY should have less influence on the covariance structure at that $T$. The regular Gaussian function (with the exponent of 2) is not used here because it falls off too slowly. The resultant yearly data chunk for the same DOY has a smooth transition between the chunks, which are concatenated together and fed to the EOF analysis. The super-Gaussian window approach differs from K14 in that K14 selects data 60 days before and after the current DOY. This is equivalent to applying the boxcar function, which produces discontinuity between yearly data chunks (e.g., the transition from one yearly data chunk to another is not continuous). Application of the super-Gaussian function avoids such discontinuity and leads to a reduction in the noise in the eigenvalues of

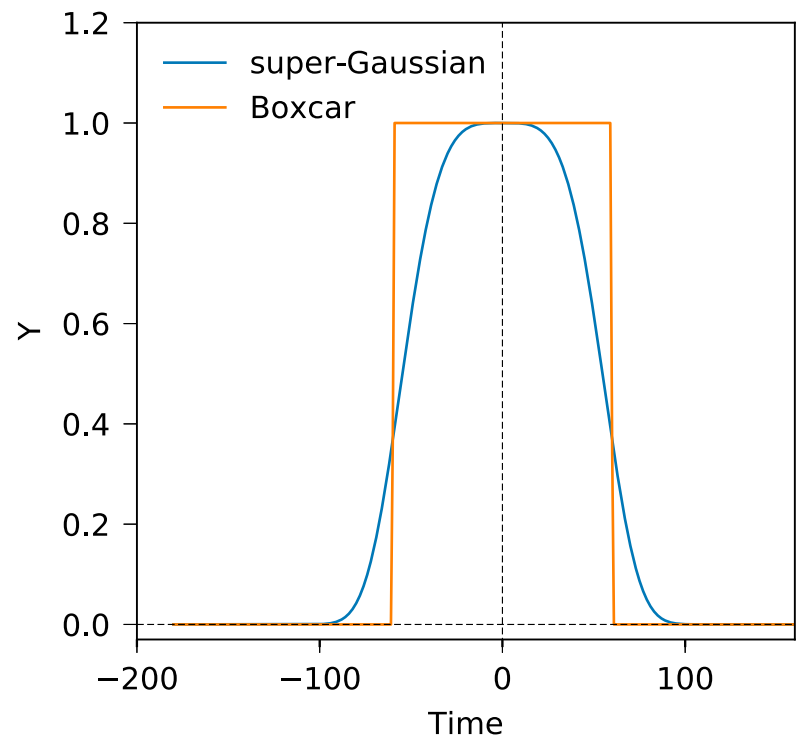

FIG. 1. The boxcar vs super-Gaussian function as a function of days. Half window size $W$ is 60 days.

precipitation anomalies. The test for OLR is discussed in the appendix.

The half-width $W$ is a free parameter. Consider two limits: if $W$ is too small (e.g., 30 days or less), the sample size is not sufficient to yield stable EOFs for intraseasonal oscillation, leading to noisy eigenvalues; if $W$ is too large, the dependence on DOY gradually decreases. We choose to use $W=60$ after some initial tests. Figure 1 shows the super-Gaussian and boxcar functions as a function of time. The EOFs are not sensitive to the exact values of $W$, as also found in K14, indicating that the method is robust overall.

The DOY-dependent local EOF analysis for each $T$ may be written in the standard singular value decomposition (SVD) form as

$$
\hat{F}(t, T)=\mathbf{U} \mathbf{\Lambda} \mathbf{V}^{\mathrm{T}},
$$

where $\mathbf{U}$ is the orthonormal spatial empirical function in each column, $\boldsymbol{\Lambda}$ is a diagonal matrix with each singular value in the diagonal entry, $\mathbf{V}$ represents orthonormal temporal function and each column of $\mathbf{V}$ is often termed the principal component time series, and the superscript $\mathrm{T}$ indicates matrix transpose. Following the convention, the spatial modes are referred to as empirical orthogonal functions. One problem with SVD is that the sign of eigenvector $\mathbf{U}$ is indefinite. We choose the sign to achieve the maximum pattern correlation between the local EOFs at two adjacent DOYs in order to maintain continuity at neighboring DOY. An analogy is often made between the EOFs and the normal modes of the boundary value problems. By this heuristic argument, applying a super-Gaussian function ensures that each 
yearly data chunk has consistent boundary conditions (zeros), which reduces noise. By convention, the principal component time series $\mathbf{V}$ from EOF analyses are often used as the index for MJO/BSISO (e.g., Wheeler and Hendon 2004), but this is not the case for the OMI index or the precipitation index discussed below. As a result, the use of a super-Gaussian function window does not artificially change the amplitude of the precipitation index.

\section{Results}

\section{a. Two-dimensional EOFs: A reference case}

We start with a two-dimensional (2D) EOF analysis of precipitation anomalies. This reference case characterizes the symmetric component of the ISOs through the EOF analysis of the equatorial precipitation anomalies averaged between $15^{\circ} \mathrm{S}$ and $15^{\circ} \mathrm{N}$ using daily $2.5^{\circ}$ TRMM-HQ data as described above (section 2a). The latitude range is used following Wheeler and Hendon (2004) for the RMM. The symmetric and antisymmetric components for variable $Z$ at latitude $\phi$ are defined as $[Z(\phi)+Z(-\phi)] / 2$ and $[Z(\phi)-Z(-\phi)] / 2$, respectively. The latitudinal average eliminates meridional propagation and, hence, greatly reduces the distinction between MJO and BSISO. We apply the 20-96-day bandpass filter and eastward filter to the $2 \mathrm{D}$ equatorial precipitation anomalies as a function of time and longitude. These precipitation anomalies are used for the EOF analysis (no DOY dependence).

Figure 2 shows the structure of the two leading EOFs as a function of longitude. The first EOF features a bipolar structure of precipitation with two seesaw centers of action in the eastern Indian Ocean and the western Pacific Ocean. EOF2 features a monopole structure with a primary center located at the Maritime Continent. This EOF structure represents canonical patterns of eastwardpropagating MJO as identified in winds or OLR in many previous studies. The explained variance of these two leading EOFs is $\sim 21 \%$ each and they are well separated from the rest eigenmodes. These two EOFs are evidently inseparable from each other (North et al. 1982), indicating that these eigenvalues/eigenvectors are degenerate. While the principal time series can also be used for indexing the symmetric component of the ISO precipitation signature, we consider that this case establishes a reference for the 3D EOF analysis in the next section that offers a more complete picture of the ISOs.

\section{b. Leading EOFs of TRMM equatorial precipitation anomalies}

The local EOF analysis is further applied to TRMM$\mathrm{HQ}$ precipitation anomalies in the equatorial area $\left(20^{\circ} \mathrm{S}-20^{\circ} \mathrm{N}\right)$. The latitude range is larger than the $2 \mathrm{D}$

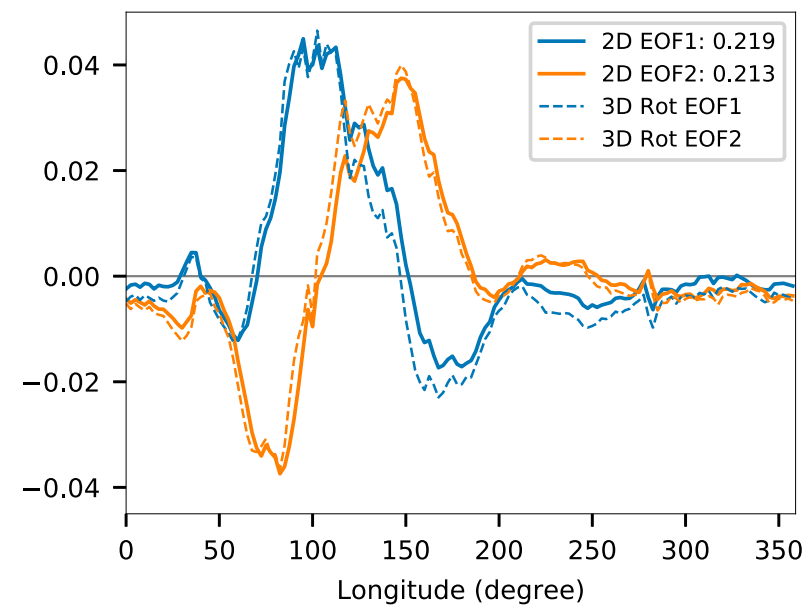

FIG. 2. Zonal structure of the two leading 2D EOFs from filtered equatorial precipitation summed between $15^{\circ} \mathrm{S}$ and $15^{\circ} \mathrm{N}$ (solid) and latitudinal sum of $3 \mathrm{D}$ precipitation EOFs after rotating the leading EOFs (dashed).

EOF analysis $\left(15^{\circ} \mathrm{S}-15^{\circ} \mathrm{N}\right)$ in the preceding section, and it is chosen following K14 for OLR. Figure 3 a shows that this EOF analysis identifies two leading EOFs that are well separated from the rest modes for all DOY. The fractional explained variance (EV) of these two EOFs is identical at all DOY to numerical precision as a result of eastward filtering. The explained variances show two peaks in $T$ : one in midwinter and the other in midsummer. The peak EV of the first EOF pair is $21 \%$ (10.5\% each) at DOY 45 (15 February) and 30\% (15\% each) at DOY 212 (1 August in a nonleap year). These EV values are lower than that for OLR (Fig. A1), which are $\sim 18 \%$ and $\sim 17 \%$ in the two seasons, partly because OMI uses a narrow band (30-90 days). If the same 3090-day band is used, the EV increases to $15 \%$ and $20 \%$ in winter and summer, respectively. Nevertheless, we use this slightly broader band to maintain consistency with the ISO index described later. A serious problem with these eigenmodes is that the symmetric structures (the latitudinal mean) of these first EOFs vary rapidly as a function of DOY (Figs. 3b,c), indicating that they are not stable through the year. This is caused by eigenvalue degeneracy: the first EOF pair is nearly identical for all DOY, and the eigenvectors associated with degenerate eigenvalues are not unique. Because of this nonuniqueness, they are not always in pace and are significantly different from those identified in Fig. 2. The rapid variation makes it difficult to unambiguously link the phases with geographical regions at all DOYs.

We address the difficulty of physical interpretation by using the properties of eigenvalue degeneracy. It is well known that all linear combinations of these degenerated eigenvectors are equally valid matrix solutions. 
(a) Explained Variance: first 4 EOF pairs

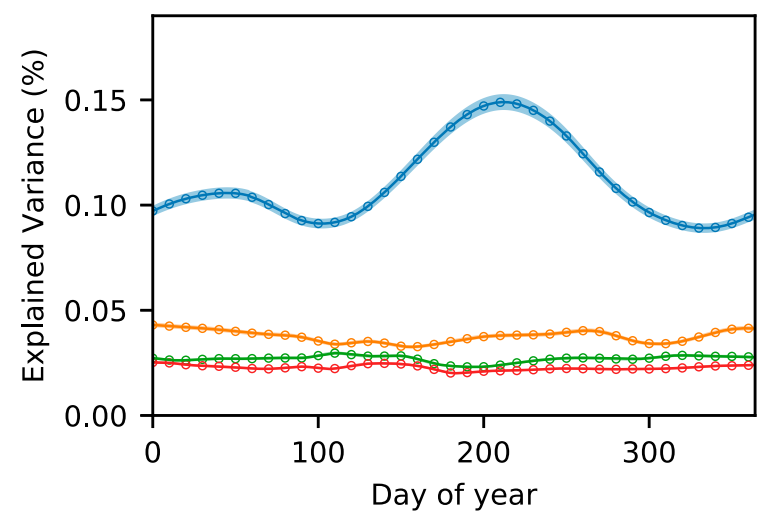

(b) EOF1 sym

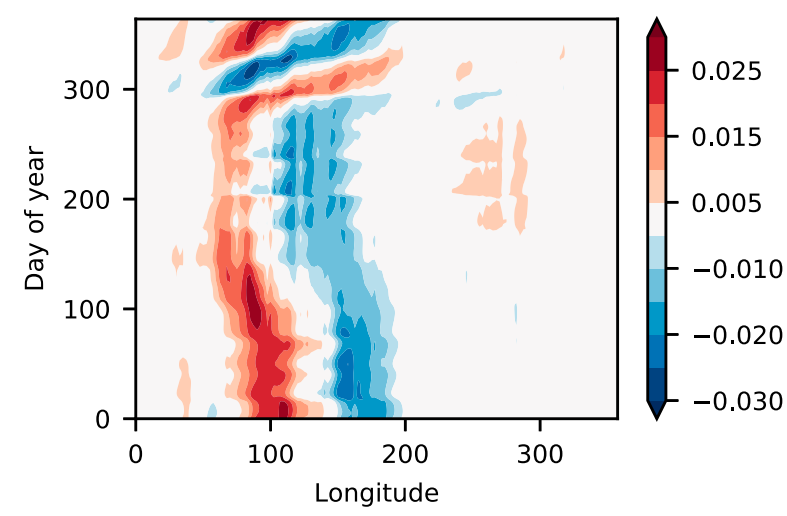

(c) EOF2 sym

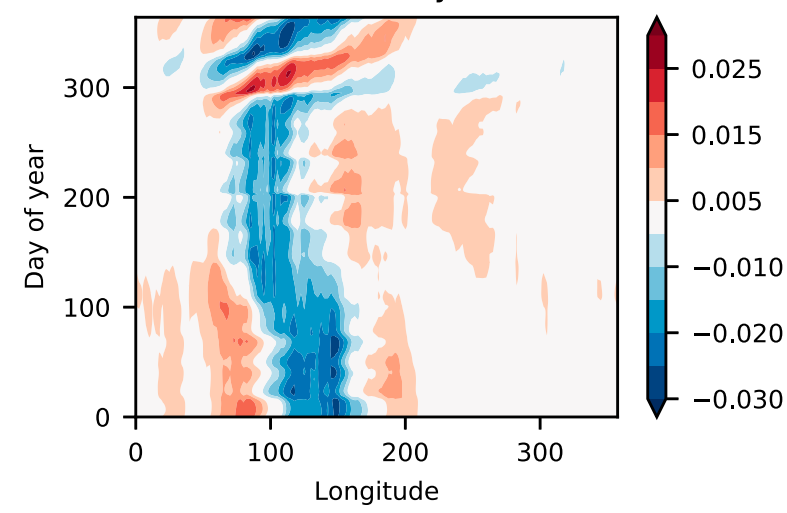

FIG. 3. (a) Explained variance as a function of the day of the year for the first four EOFs derived from the TRMM-HQ $2.5^{\circ}$ daily precipitation data $\left(20^{\circ} \mathrm{S}-20^{\circ} \mathrm{N}\right)$. Solid curves show EOF1; shading is the uncertainty range of EOF1 derived from the North's test, and circles indicate EOF2 every 10 days. Note that explained variances of EOF2 are nearly identical to EOF1 with the relative error being $10^{-3}$. (b),(c) Symmetric structures of EOF1 and EOF2.
We apply a rotation operation-a special form of linear transformation-to the degenerate eigenvectors. Specifically, we rotate the first two EOFs by applying a rotation matrix with angle $\theta$ to the degenerated eigenvector pair (EOF1, EOF2), which may be written in matrix form as

$$
\left[\begin{array}{l}
\mathrm{EOF} 1^{\prime} \\
\mathrm{EOF}^{\prime}
\end{array}\right]=\left[\begin{array}{cc}
\cos \theta & -\sin \theta \\
\sin \theta & \cos \theta
\end{array}\right]\left[\begin{array}{l}
\mathrm{EOF} 1 \\
\mathrm{EOF} 2
\end{array}\right]
$$

where the prime indicates the eigenvector after rotation. The rotation angle $\theta$ is a free parameter and there is no restriction on $\theta$ mathematically. On the other hand, it is crucial to maintain consistency in the symmetric structures for all the DOY for the sake of physical interpretation. We match the symmetric structure of rotated EOFs [left side of Eq. (3)]. For this purpose, we select a value of $\theta$ that broadly places the center of convection in the Indian Ocean following the convention established by Wheeler and Hendon (2004). Specifically, for each DOY, we seek a $\theta$ that maximizes the latitudinal average of one arbitrary EOF at longitude $\Phi$. This is achieved by rotating EOFs for $\theta$ with a $1^{\circ}$ increment for $\theta$ within $[-\pi, \pi)$ using Eq. (3), and searching the EOF that maximizes at $\Phi$ in its symmetric structure.

The above rotation operation differs from the canonical rotated EOF (REOF) technique discussed in the literature (Richman 1986). The REOF technique applies rotation to a number of EOFs and the exact number of EOFs subject to rotation is empirically determined. A consequence of rotation is that REOFs do not preserve orthogonality in the spatial modes and principal components simultaneously (Jolliffe 1995). Our method avoids this deficiency as we only apply the rotation to eigenvectors associated with the degenerate eigenvalue pair. As both the rotation matrix and the spatial basis are orthonormal, the rotated EOFs remain orthonormal and the principal time series are kept orthogonal. The rotation operation does not change either the reconstructed patterns from projection to these EOFs or the total explained variance by the two degenerated modes. The rotation operation allows us to achieve better interpretability without sacrificing mathematical properties of the original EOFs.

As stated earlier, $\Phi$ is determined to match the symmetric structure of rotated EOFs. We chose a $\Phi$ that minimizes the zero-lag correlation between the two time series derived by projection of the filtered precipitation anomalies onto the rotated EOFs, as discussed in detail in the next section. For the discussion below, we use $\Phi=$ $67.5^{\circ}$, that is, in the Indian Ocean.

A time-longitude diagram of the symmetric and antisymmetric components is shown in Fig. 4. The symmetric 
(a) Rain EOF1, symmetric

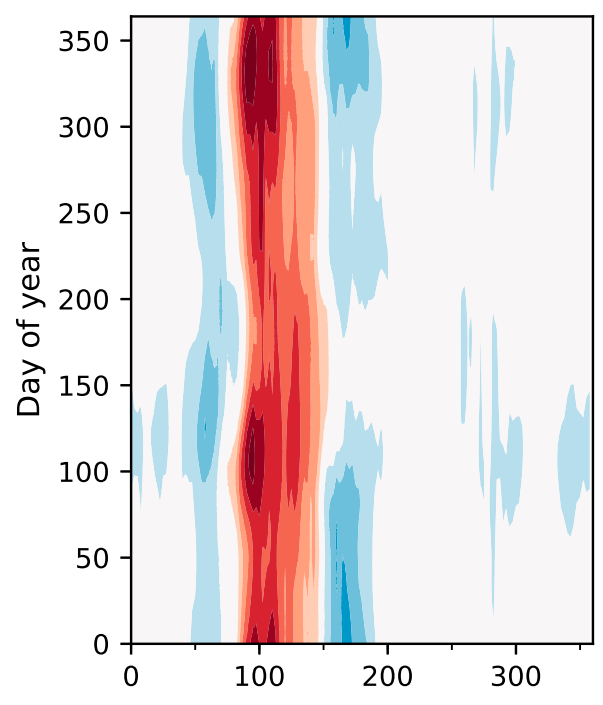

(c) Rain EOF1, antisym

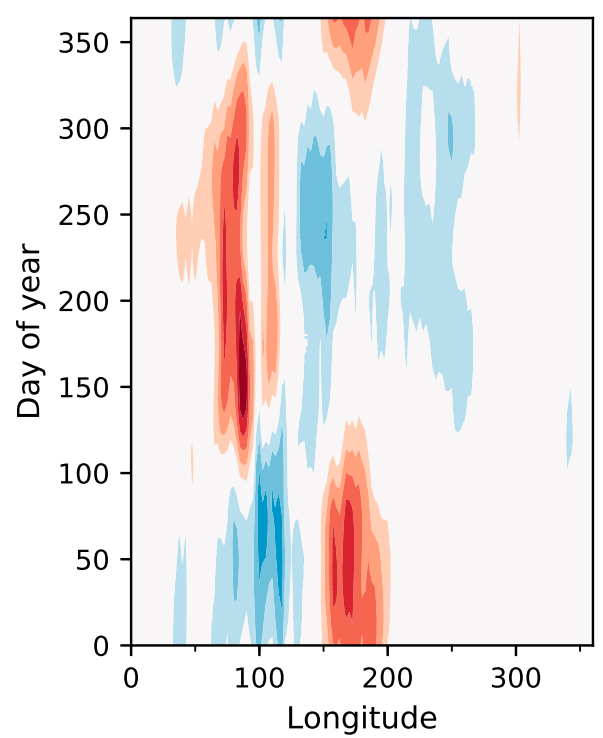

(b) Rain EOF2, symmetric

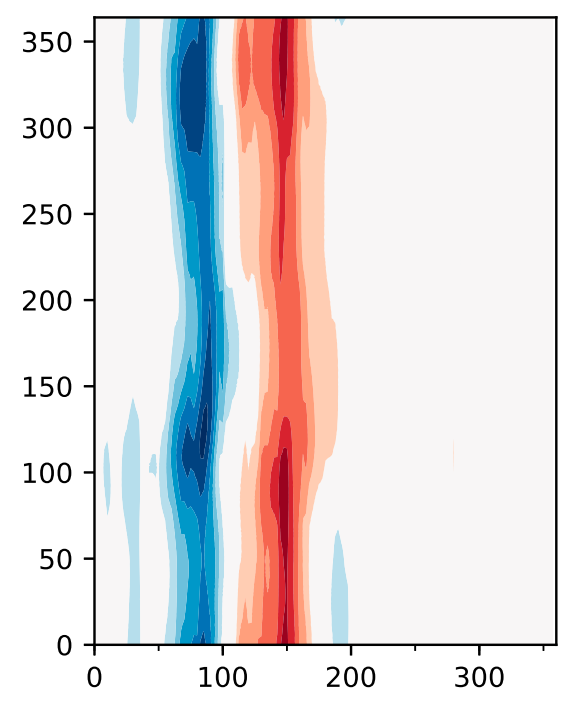

(d) Rain EOF2, antisym

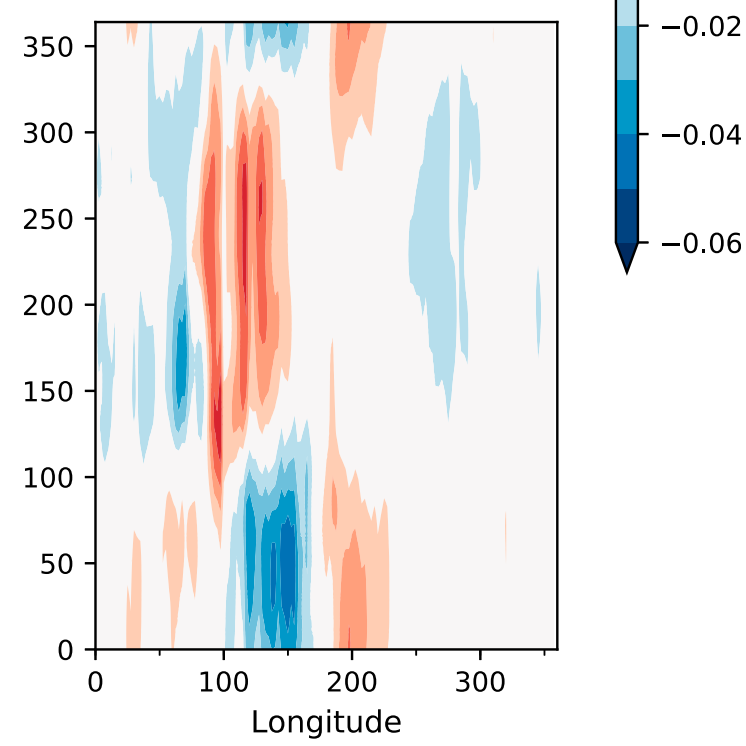

FIG. 4. (a),(b) Symmetric and (c),(d) antisymmetric components $\left(15^{\circ} \mathrm{S}-15^{\circ} \mathrm{N}\right)$ of the first two EOFs from the TRMM-HQ precipitation anomalies.

structures of EOF1 (Fig. 4a) show a monopole structure with enhanced rainfall in the Maritime Continent. These patterns persist throughout the year with little disruption except for some weak seasonal variations. The symmetric structures of EOF2 (Fig. 4b) show a dipolar structure with enhanced rainfall in the Indian Ocean and suppressed rainfall in the western Pacific Ocean. The zonal structure may also be compared with the result from the 2D EOF. The dashed curves in Fig. 2 are the latitudinal sum of the first two EOFs. The structure closely matches that from the 2D EOFs, indicating that the symmetrical structure of the precipitation anomalies is preserved in the 3D local EOF analysis. The antisymmetric components show a significant seasonal contrast (Figs. 4c,d). The spatial patterns of rotated EOFs [Eq. (3)] at $T=0,50,100, \ldots$, 300 days are further illustrated in Fig. 5 ( $T=0$ corresponds to 1 January). Rain EOFs in the Maritime Continent at $T=0$ and 50 days are centered south of the equator, similar to the reference case. The $T=$ 140-300-day patterns show a northwest-southeasttilted structure, indicating the BSISO. The pattern at 
EOF1
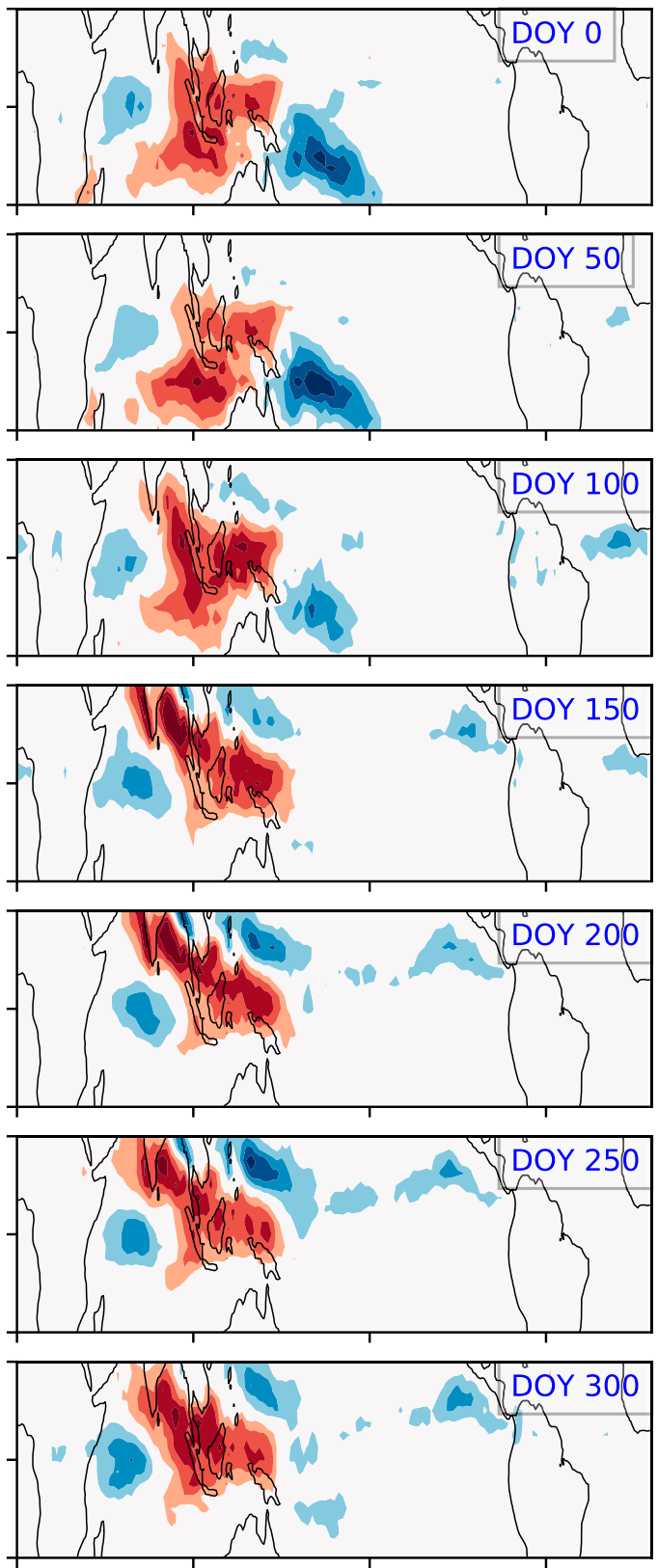

EOF2
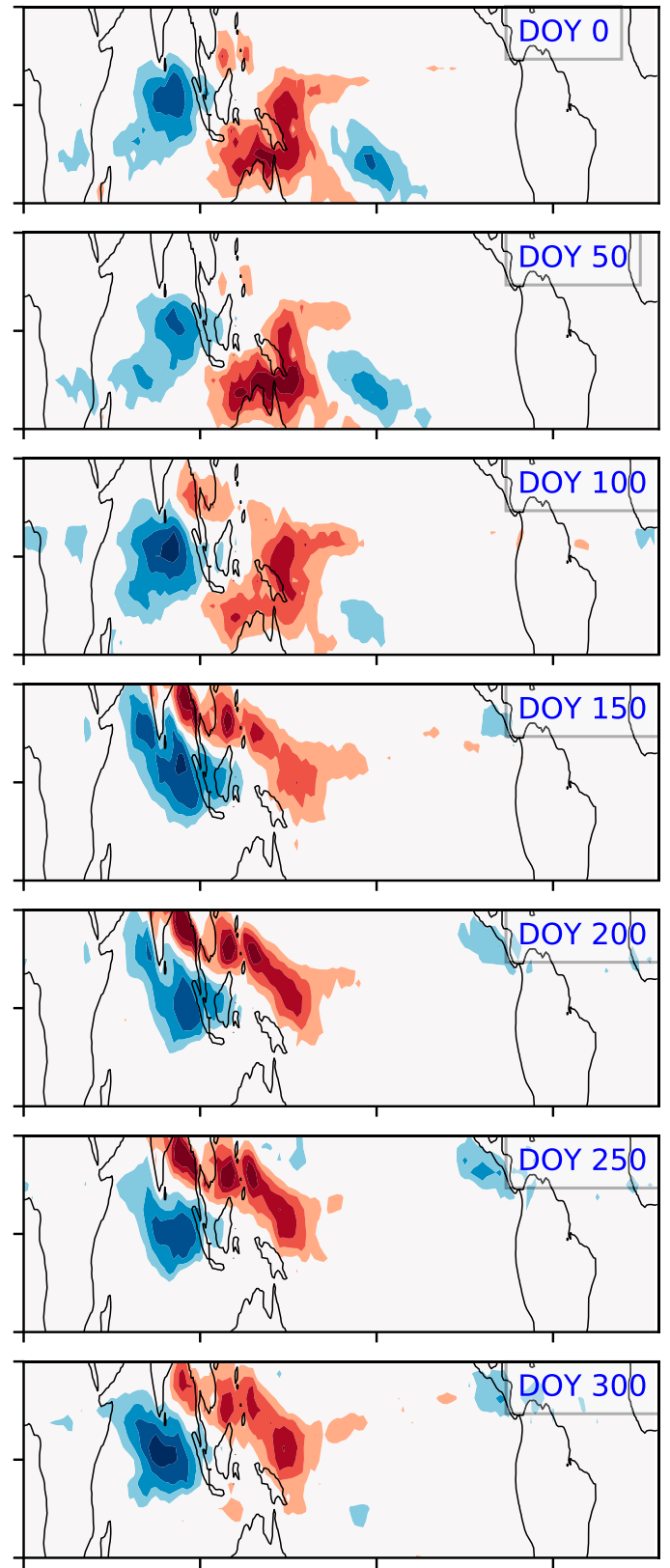

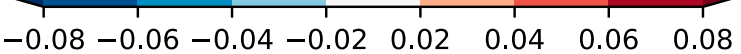

FIG. 5. Spatial patterns of (left) EOF1 and (right) EOF2 from TRMM-HQ $\left(20^{\circ} \mathrm{S}-20^{\circ} \mathrm{N}\right)$ on seven different days of the year: (top to bottom) $0,50,100, \ldots$, and 300 .

$T=100$ days shows structures that appear to be a blend of the classical MJO and BSISO.

\section{c. Precipitation index for tropical intraseasonal oscillation}

The precipitation index for the ISOs described below is based on the rotated EOFs. Instead of projecting eastward precipitation anomalies onto the rotated EOFs, we follow K14 and keep all the westward and mean components in the 20-96-day bandpass-filtered TRMM daily data (the non-HQ version) from 1998 to 2018 for projection. The resultant two time series are normalized by the respective standard deviation. The normalized time series are then used as the precipitation 
index for the ISOs. Because of the addition of the westward and mean components, the two daily time series are not orthogonal in general, but the deviation from orthogonality is minor, since the westward and mean components contribute a much smaller variance to the total variance than the eastward components, as we will see from the cross correlation between the two later.

We further develop a real-time version of the precipitation-based index for tropical intraseasonal oscillation (PII). The key consideration is that the real-time version avoids using bandpass filtering over time, which tends to cause difficulty at the leading edges of the precipitation time series. Following Wheeler and Hendon (2004), Kikuchi et al. (2012), and $\mathrm{K} 14$, the precipitation anomalies are computed by removing the first three harmonics of the mean seasonal cycle and the time mean at individual grid points. Then the precipitation anomalies are processed using a time-window technique and further projected onto the rotated precipitation EOFs. Specifically, the mean of the previous 40 days is first subtracted from the precipitation anomalies; and then the latter are smoothed by using a 9-day running average and tapered toward the end of the time series as in K14. Real-time PII (rPII) is obtained by projecting the rain anomalies onto the two spatial EOF patterns of 20-96-day eastward-filtered and rotated EOFs, and further normalized by the respective standard deviation of each time series (Fig. 4). The 40-day average is used to achieve the maximum correlation between PII and its real-time counterpart, which is $\sim 0.9$ across all the seasons.

For illustration, we examine the PII index for the MJO event observed during the Dynamics of the Madden-Julian Oscillation (DYNAMO) field campaign during the last 3 months of 2011 (Zhang 2013; Yoneyama et al. 2013; Sobel et al. 2014; Wang et al. 2015 , 2016). The bandpass-filtered precipitation anomalies are averaged between $15^{\circ} \mathrm{S}$ and $15^{\circ} \mathrm{N}$ from 1 October to 31 December 2011. Figure 6a indicates that convection/precipitation anomalies associated with this MJO event started in the Indian Ocean in the middle of October 2011 (Yoneyama et al. 2013; Sobel et al. 2014; Wang et al. 2015, 2016). Figure 6b shows the phase diagram of PII during this period, and the real-time version is shown in Fig. 6c. Both PII and rPII are able to capture the initiation and eastward propagation of this MJO event. The pattern of PII in the phase diagram is broadly similar to the OMI index (Fig. 6c of K14) as they both characterize the same phenomena but different aspects. For comparison, the OMI and RMM index during the same period are shown in Figs. 6d and 6e, respectively. OMI and PII
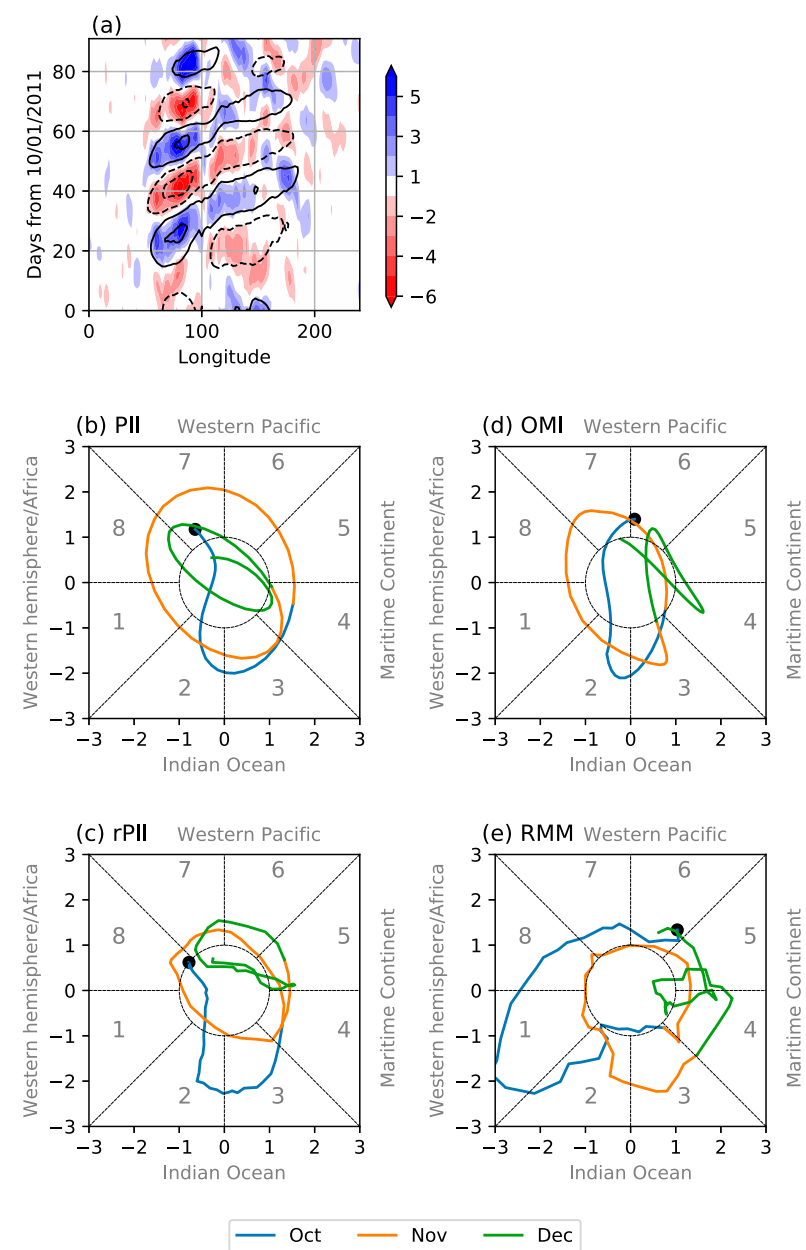

FIG. 6. (a) Reconstructed precipitation anomalies averaged between $15^{\circ} \mathrm{S}$ and $15^{\circ} \mathrm{N}$ (solid: $1 \mathrm{~mm} \mathrm{day}^{-1}$; dashed: $-1 \mathrm{~mm} \mathrm{day}^{-1}$ ) and bandpass-filtered precipitation anomalies (shading). (b) Phase diagram of precipitation index from 1 October to 31 Dec 2011 (the DYNAMO case). (c)-(e) As in (b), but for the real-time version, OMI, and RMM, respectively.

are comparable in October and November to some degree, and both differ substantially from RMM.

The similarity among these three indices may be quantified with the bivariate correlation in the boreal winter (December to March) and summer (June to September) seasons from 2000 to 2014, as summarized in Table 1. The maximum correlation between PII and OMI in winter is 0.74 with PII leading by 4 days, and it is 0.88 in summer with PII leading by 1 day. PII and OMI are well correlated in the summer season, but less so in the winter season. The correlation between PII and RMM is notably less: 0.60 at 5-day leads in summer, and 0.55 at 4 -day leads.

Figure $7 \mathrm{a}$ shows that the correlation coefficient between the two values of PII (PII-1 and PII-2) from 1998 to 2017 is approximately orthogonal at day 0 , and 
TABLE 1. Maximum values of the bivariate correlation coefficient between the daily indices for PII, OMI, and RMM during the period from 2000 to 2014 for the winter (Dec-Apr) and summer (May-Sep). The time lag of the highest correlation is shown in parentheses. Positive values mean the index in the left columns leads that in the top row.

\begin{tabular}{lllllcc}
\hline & \multicolumn{3}{c}{ Dec-Apr } & \multicolumn{3}{c}{ May-Oct } \\
\hline & PII & OMI & RMM & PII & OMI & RMM \\
PII & - & $0.74(4)$ & $0.60(5)$ & - & $0.88(1)$ & $0.55(4)$ \\
OMI & - & - & $0.74(1)$ & - & - & $0.67(2)$ \\
\hline
\end{tabular}

reaches $\sim 0.7$ at day 9 , which is roughly a quarter of the total period of the ISO identified from the EOF analysis. The PII-1 and PII-2 correlation coefficient drops slightly in winter, which is likely due to there being lower fractional variance in winter (Fig. 2a). The real-time PII shows a similar structure in the lead-lag correlation, although the peak value is lower (0.6) at similar lead-lag days (9) compared to PII because of increased noise.

\section{d. Properties of the precipitation index}

Figure 8 shows the structure of the bandpass-filtered precipitation anomalies composited upon the eight PII phases, computed as arctan(-PII2/PII1), in boreal winter (December to March) and summer (June to September) seasons, respectively, from 1998 to 2018. The composite is computed on the days when the amplitude of the PII index is greater than 1 . The left column of Fig. 8 shows that the winter intraseasonal precipitation life cycle, corresponding to the canonical MJO. The life cycle progresses eastward from the its initialization in the Indian Ocean (phases 1 and 2), to the eastern Indian Ocean in phase 3 where it strengthens, to the Maritime Continent (phases 4 and 5) where it achieves the maximum, further to the intertropical convergence zone (ITCZ) and South Pacific convergence zone (SPCZ) during

(a) Lag corr. of PI

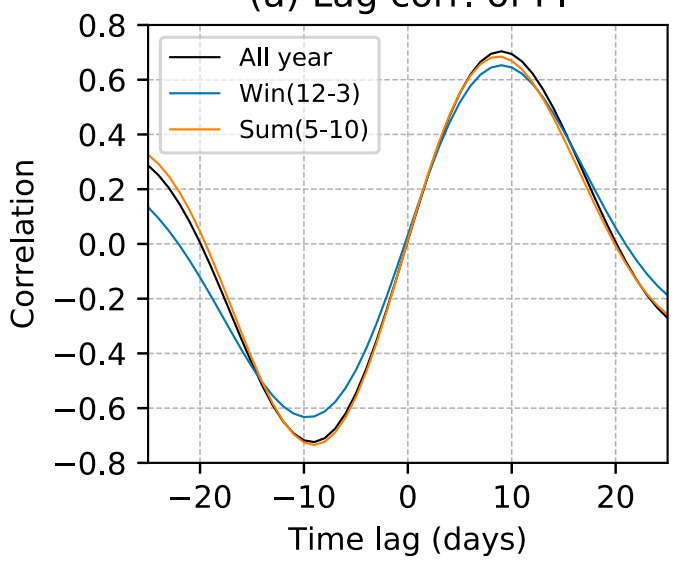

phases 5-6, where it bifurcates into to two branches, and finally to the western Pacific Ocean in the terminating phase 8 . The spatial pattern in summer differs significantly from that in winter: the primary structure is tilted northwest-southeast in nearly all phases in summer, and there is northward as well as eastward movement across the phases. Overall, the composite structure appears to be broadly similar to those based on the widely used RMM index (Waliser et al. 2009, their Figs. 11 and 12).

We further test the propagation characteristics based on the reconstructed precipitation anomalies. This is necessary as there is no guarantee that the modes from the multivariate EOF analysis are propagating signals in general. Wang et al. (2018) suggested that it is useful to cross-check the propagation with lag correlation. Figure 9a shows the lag correlation of precipitation anomalies averaged between $80^{\circ}$ and $90^{\circ} \mathrm{E}$ against precipitation anomalies at a reference area $\left(5^{\circ}-10^{\circ} \mathrm{N}\right.$, $80^{\circ}-90^{\circ} \mathrm{E}$ ) in the boreal summer season, which identifies a coherent northward propagation. Similarly, northward propagation can also be identified in the South China Sea region with a reference area $\left(5^{\circ}-10^{\circ} \mathrm{N}\right.$, $\left.110^{\circ}-120^{\circ} \mathrm{E}\right)$. Eastward propagation is tested using two reference areas $\left(5^{\circ} \mathrm{S}-5^{\circ} \mathrm{N} 80^{\circ}-90^{\circ} \mathrm{E}\right.$ and $5^{\circ} \mathrm{S}-5^{\circ} \mathrm{N}, 110^{\circ}-$ $120^{\circ} \mathrm{E}$ ) in two seasons (Figs. 9c-f). Relatively slow propagation $\left(\sim 5 \mathrm{~m} \mathrm{~s}^{-1}\right)$ is found from the Indian Ocean $\left(40^{\circ} \mathrm{E}\right)$ to the western Pacific Ocean $\left(150^{\circ} \mathrm{E}\right)$, while the precipitation anomalies speed up the eastward propagation after $150^{\circ} \mathrm{E}$.

\section{e. MJO versus $B S I S O$ in TRMM precipitation}

One intriguing result of our EOF analysis is that the fractional variance $(\mathrm{EV})$ in summer is greater than that in winter in precipitation EOFs (Fig. 2a). This implies that the precipitation associated with the BSISO is

\section{(b) Lag corr. of Realtime PI}

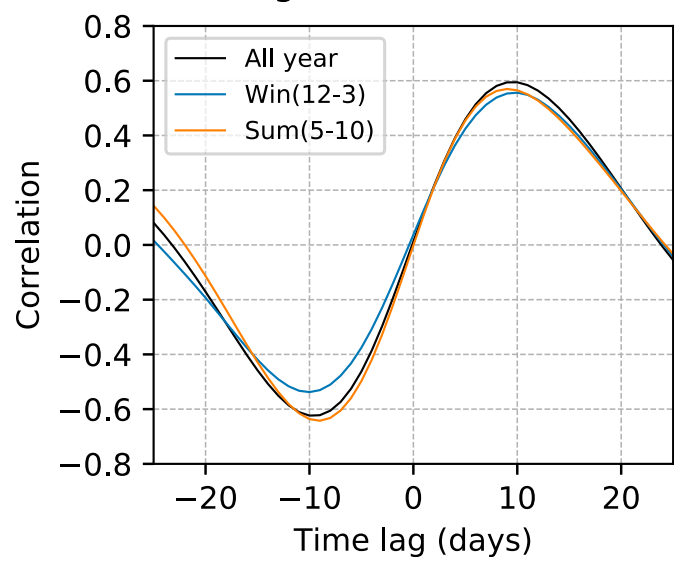

FIG. 7. (a) Correlation between PII-1 and PII-2. (b) As in (a), but for real-time version. 

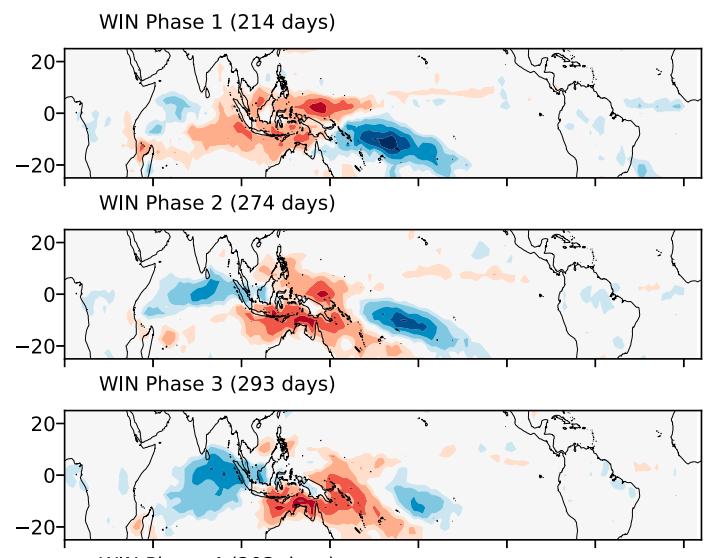

WIN Phase 4 (203 days)
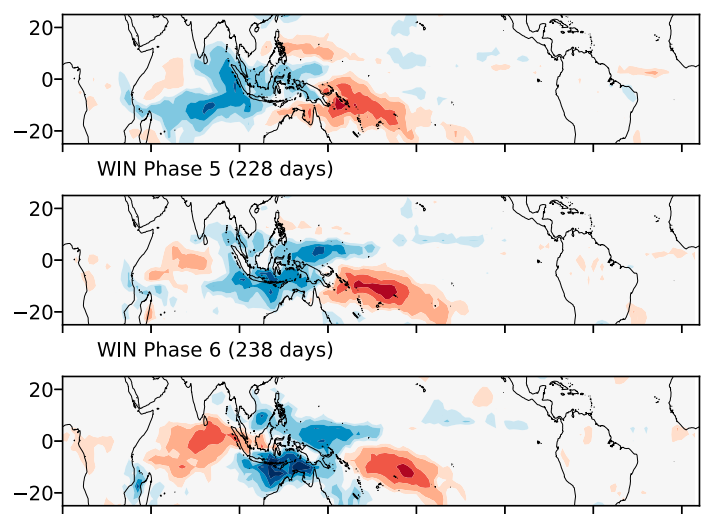

WIN Phase 7 (255 days)

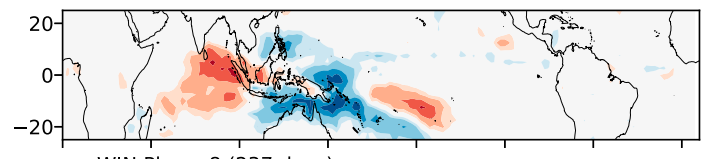

WIN Phase 8 (237 days)
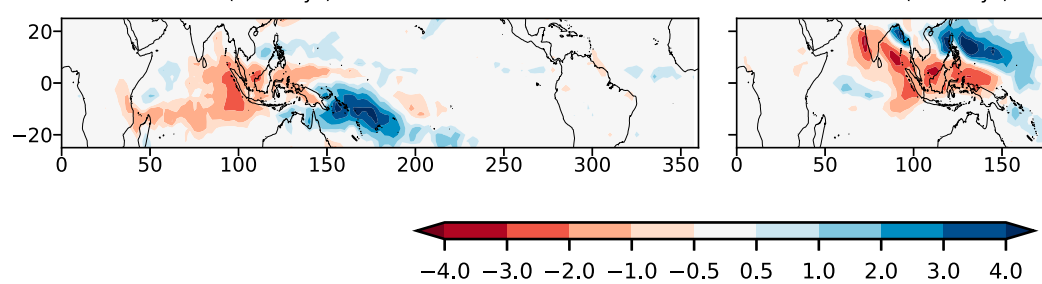

FIG. 8. Composite of bandpass-filtered precipitation anomalies in (left) boreal winter (December to March) and (right) boreal summer (June to September) on individual PII phases with amplitude greater than 1.2.

more coherent than the MJO. The seasonal contrast in ISO was also noted in Sobel et al. (2010), which showed that intraseasonal variance of TRMM precipitation is much higher in boreal summer than winter. Nevertheless, this result differs from EV derived from the EOF analysis of OLR, which shows that EV-MJO is higher than EV-BSISO (K14 and Fig. A1). This inconsistency might be due to the different variables used or possibly because of the relatively shorter data length of the TRMM-HQ data (17 years) compared to OLR ( $\sim 40$ years). Here, we test whether or not the explained variances of the BSISO or MJO change in different
SUM Phase 1 (186 days)
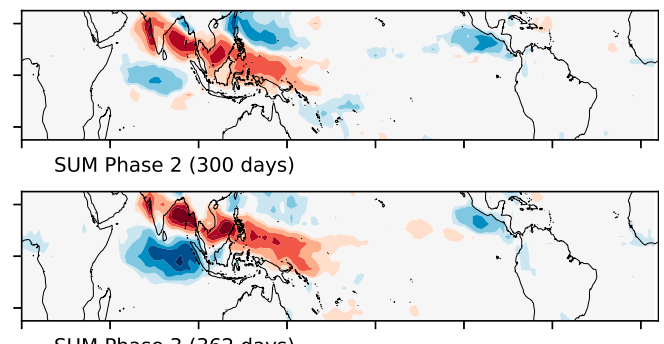

SUM Phase 3 (362 days)

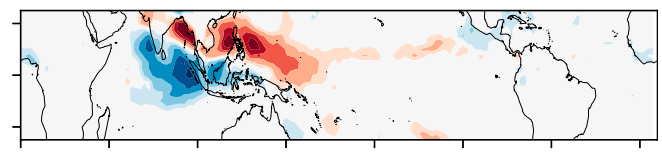

SUM Phase 4 (183 days)

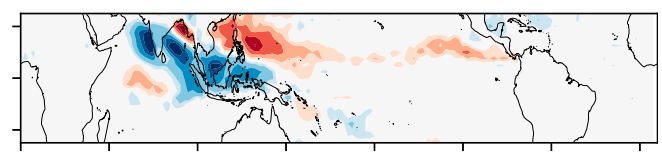

SUM Phase 5 (194 days)

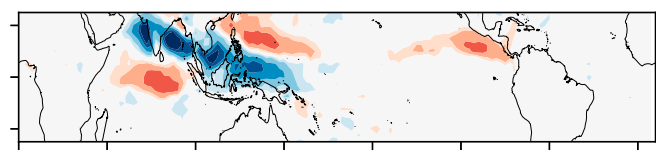

SUM Phase 6 (339 days)

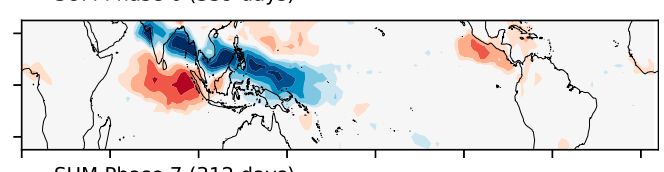

SUM Phase 7 (312 days)

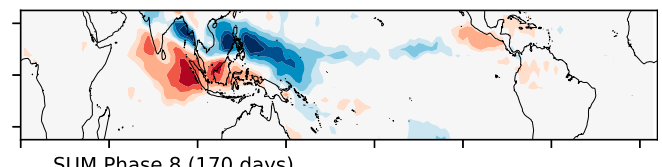

SUM Phase 8 (170 days)

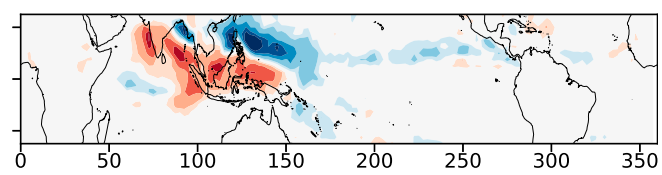

decades. We perform the same local EOF analysis using OLR from every 10 years, centering on 1985, 1990, 1995, 2000, 2005, and 2010.

Figure 10 shows that the explained variance from the six different local EOF analyses. In all these EOF results, the first two eigenvalues or EVs are identical, and they are much larger than the other modes, suggesting that the 10-yr period provides sufficient samples for the EOF analysis. The fractional explained variances as a function of DOY differ markedly during different decades: the EV peak at boreal summer (e.g., $T=220$ ) is higher than the peak in winter (e.g., $T=50$ ) from 1980 
(a) IND Sum

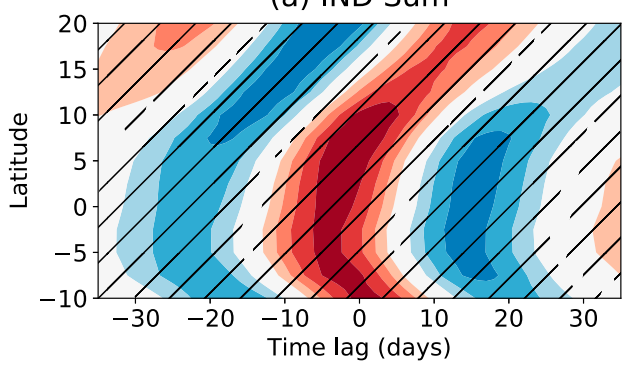

(c) IND Sum

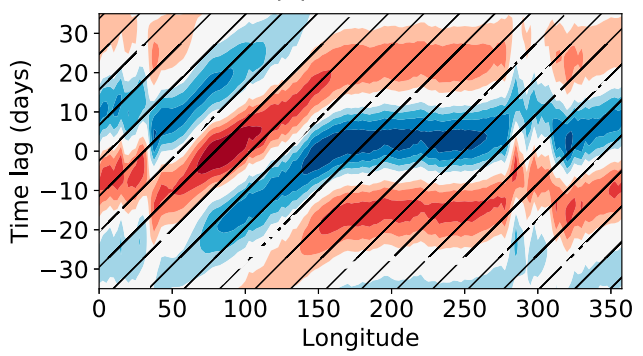

(e) Ind Win

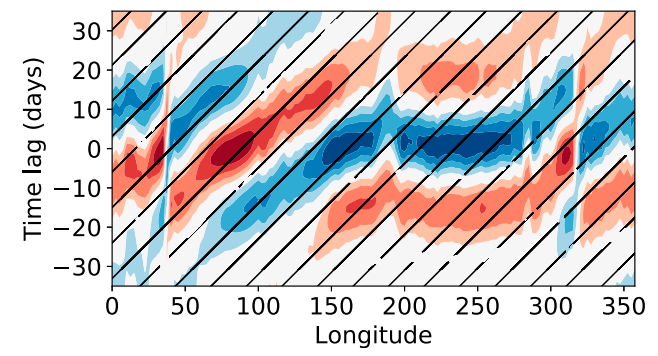

(b) SCS Sum

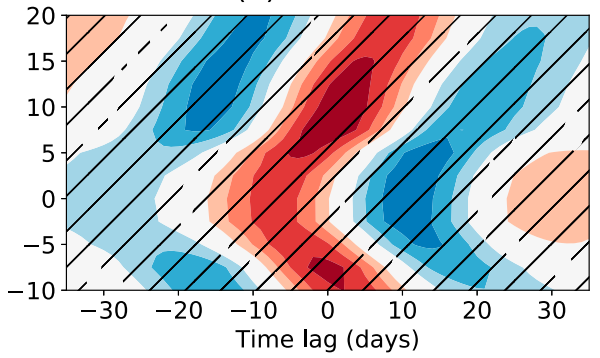

(d) SCS Sum

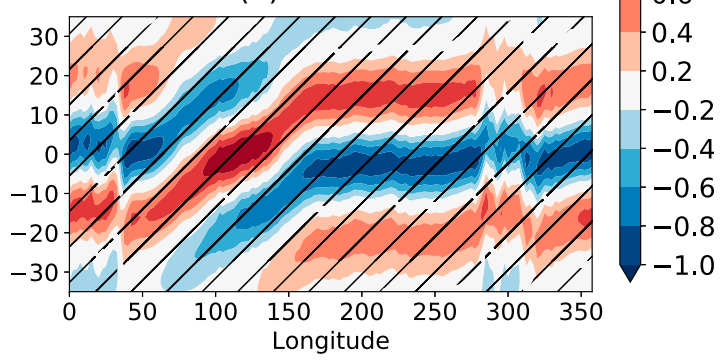

(f) SCS Win

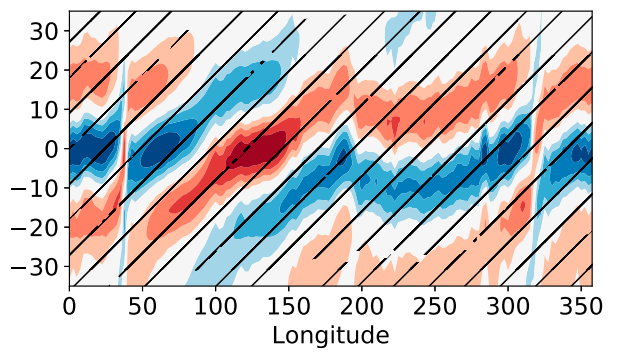

FIG. 9. Lag correlation of reconstructed and bandpass-filtered rain anomalies based on the reference areas $\left(5^{\circ}-10^{\circ} \mathrm{N}\right.$, $110^{\circ}-120^{\circ} \mathrm{E}$ and $5^{\circ} \mathrm{S}-5^{\circ} \mathrm{N}, 110^{\circ}-120^{\circ} \mathrm{E}$ ). Dashes indicate the correlation is statistically significant at the $95 \%$ level.

to 2000, while the opposite is true from 1995 to 2010. Comparing at $T=220$ between the top and bottom rows of Fig. 10 indicates that BSISO EV is $0.18-0.25$ in the latter half period (i.e., the decades centered around 2000, 2005, and 2010) and below 0.15 in the first half period. In contrast, the MJO EV $(T=50)$ shows much less variability across the decades: the MJO EV varies from 0.15 to 0.20 through the period 1980-2015, although there is some indication that MJO EV is weaker during the latter period. Results from the OLR data confirm the results of precipitation in that EV in boreal summer is higher than in winter during the period 2000-10.

There are several plausible explanations for the relatively higher EV in the northern summer. It is likely that the BSISO is more coherent and/or that background noise is lower, or a combination of the two factors. We first compute the lag correlation of bandpass-filtered precipitation anomalies to test if intraseasonal propagation is more coherent. Figures $11 \mathrm{a}$ and $11 \mathrm{~b}$ compare the patterns of the lag correlation of OLR (averaged over $\left.110^{\circ}-120^{\circ} \mathrm{E}\right)$ against the bandpass-filtered (20-96-day) OLR anomalies averaged in the reference area $\left(5^{\circ}-\right.$ $10^{\circ} \mathrm{N}, 110^{\circ}-120^{\circ} \mathrm{E}$ ) in the two periods $1980-90$ and 2000-10. The correlation is notably higher in the latter period, indicating more coherent propagation during 2000-10. Lag correlation based on the reconstructed OLR anomalies (Figs. 11c,d) is similarly more coherent in this period. For eastward propagation, we examine the lag correlation of OLR (averaged between $5^{\circ} \mathrm{S}$ and $5^{\circ} \mathrm{N}$ ) against the bandpass-filtered (20-96-day) OLR anomalies averaged in the reference area $\left(5^{\circ} \mathrm{S}-5^{\circ} \mathrm{N}\right.$, $\left.110^{\circ}-120^{\circ} \mathrm{E}\right)$. Figures $11 \mathrm{e}$ and $11 \mathrm{f}$ show that the contour for the correlation coefficient $=0.2$ in lag correlation patterns of bandpass-filtered anomalies extends to $200^{\circ} \mathrm{E}$ during $2000-10$, while it only extends to $150^{\circ} \mathrm{E}$ during 1980-90, suggesting more coherent eastward propagation in the later period. The slope of the lag correlation is also less in the second period, suggesting faster propagation. Propagation in the reconstructed 
(a) $1980-1990$

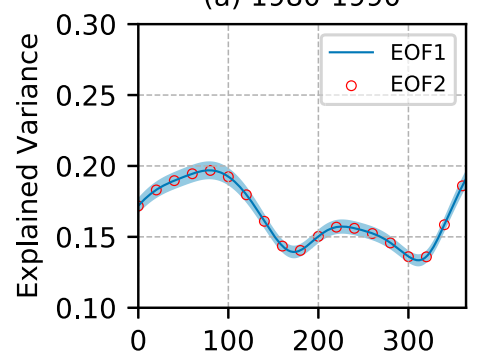

(d) $1995-2005$

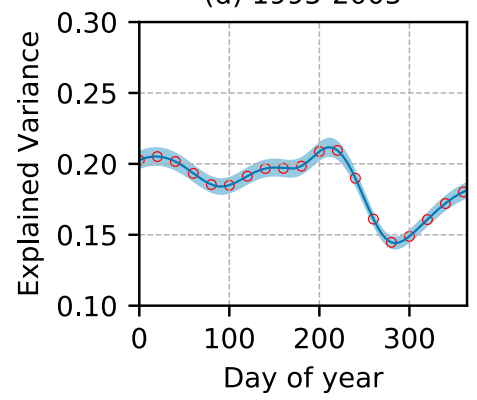

(b) $1985-1995$

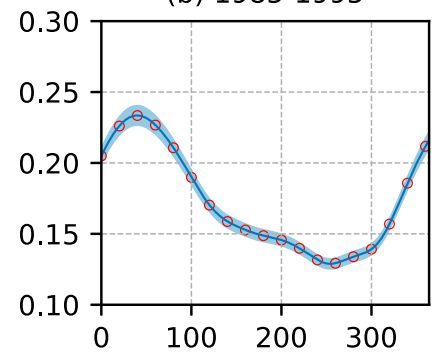

(e) $2000-2010$

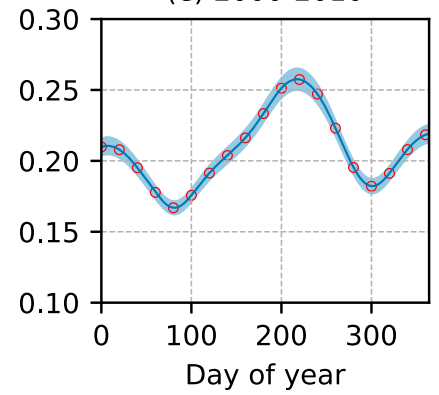

(c) $1990-2000$

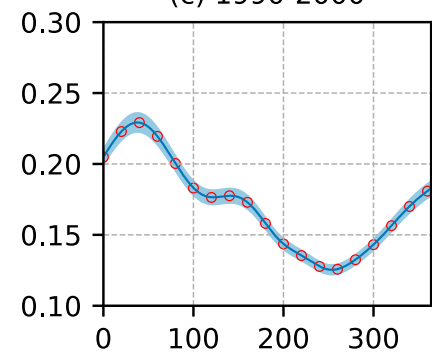

(f) $2005-2015$

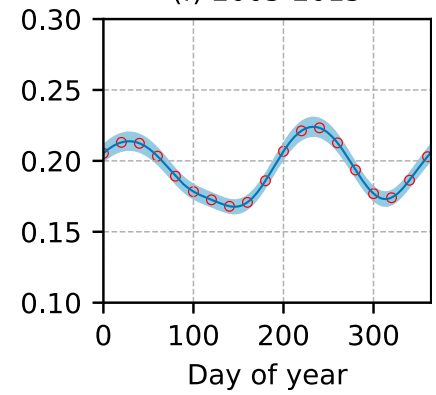

FIG. 10. Explained variance of the first two EOFs as a function of DOY from the local EOF analysis applied to OLR anomalies every 10 years.

OLR fields (Figs. 11g,h) shows similar results. In conclusion, the above lag correlation analysis offers evidence that decadal variation of the explained variance by the BSISO occurs because the BSISO is more coherent and it is less likely that it is due to decadal variation of noises. This result is independent of the EOF analysis, as the results hold for bandpass-filtered OLR anomalies.

\section{f. Application to subseasonal prediction}

The real-time version of PII may be applied to a gridded precipitation forecast from numerical weather prediction systems. In this section, we apply rPII to the EMCWF S2S reforecast data, which are part of the WMO/S2S database project (Vitart et al. 2017). We follow the methodology and steps for the forecast of real-time OMI developed in Wang et al. (2019). PII and its real-time counterpart are computed by projecting TRMM $3 \mathrm{~B} 42$ HQ precipitation anomalies (1998 to the present) onto the rotated EOFs described in section 3b. Precipitation anomalies from the forecast are computed and interpolated to the same $2.5^{\circ}$ grid as these EOFs and projected onto the rotated EOFs.

First, an example is used to illustrate how forecast MJO rain anomalies may be diagnosed with the realtime PII index. The case we examine is the DYNAMO MJO case (Fig. 6). As in Wang et al. (2019), we examine the ensemble reforecast of the DYNAMO MJO event initialized on 1 October 2011. The ECMWF version is 1 October 2015, model cycle CY41R1.
Figure $12 \mathrm{a}$ shows the predicted rPII from the 11 ensemble members (light gray) and the ensemble mean (blue). This reforecast is initialized on 1 October 2011 and integrated for 45 days to the first two weeks of November. rPII in both the forecasts and observations (black) lies in phases 7 and 8 in the first 10 days (dry conditions over the Indian Ocean). Both predicted and observed rPIIs strengthen with amplitude greater than 1 around the week 10-15 October. Thereafter, the predicted and observed rPII maintained their strength in phases 8 and 1, and further weakened in the Indian Ocean (Fig. 12b). During later October and early November, the predicted rPII index is underestimated compared to observation, indicating that the predicted MJO, contrary to observations, failed to cross the Maritime Continent. The spatial pattern of precipitation may also be reconstructed from rPII using the EOF patterns. Figure $12 \mathrm{~b}$ shows the time-latitude diagram of the reconstructed precipitation anomalies averaged at the equator (between $10^{\circ} \mathrm{S}$ and $10^{\circ} \mathrm{N}$ ) for this reforecast. The eastward propagation of dry anomalies during the first two weeks of October and initialization of MJO convection in the middle of October are largely consistent with the real-time PII.

The prediction skill of the rPII index for multiple forecasts may be assessed using the bivariate correlation (e.g., Lin et al. 2008) for the reforecasts. Let $\mathbf{F}$ and $\mathbf{O}$ be the forecast and the observed rPII index; $\mathbf{F}$ and $\mathbf{O}$ are vectors with two components, rPII-1 and 
(a) BP: $1980-1990$

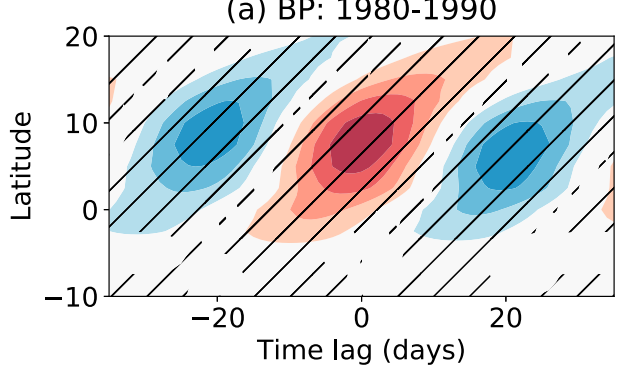

(c) Recon: 1980-1990

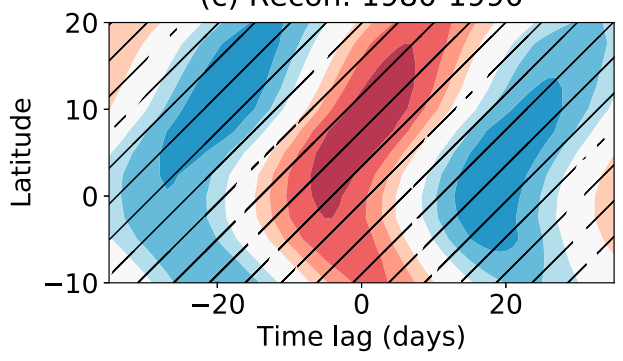

(e) BP Sum 1980-1990

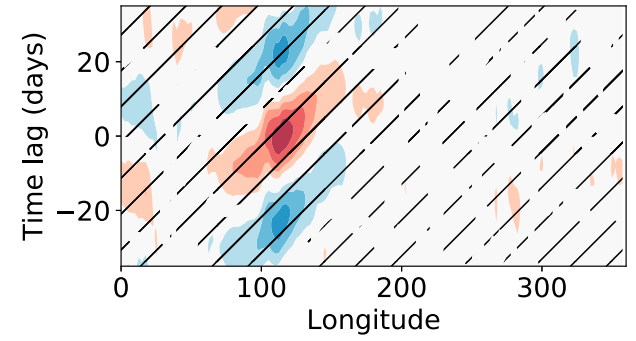

(g) Recon Sum 1980-1990

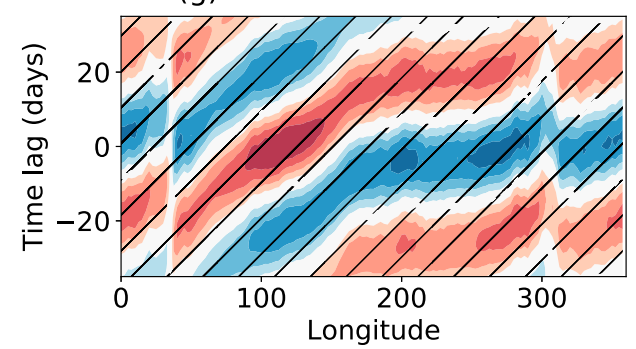

(b) BP: $2000-2010$

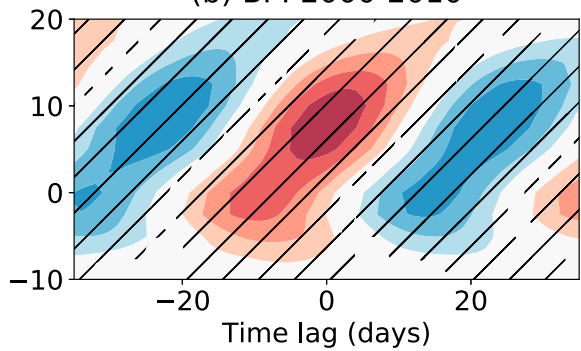

(d) Recon: 2000-2010

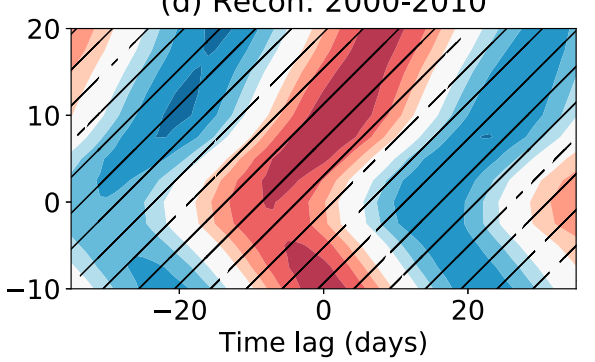

(f) BP Sum 2000-2010

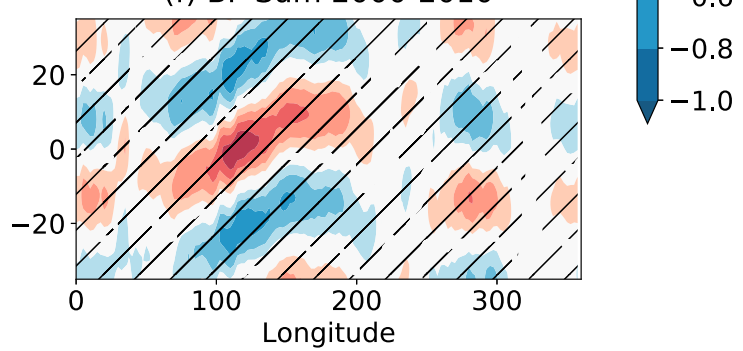

(h) Recon Sum 2000-2010

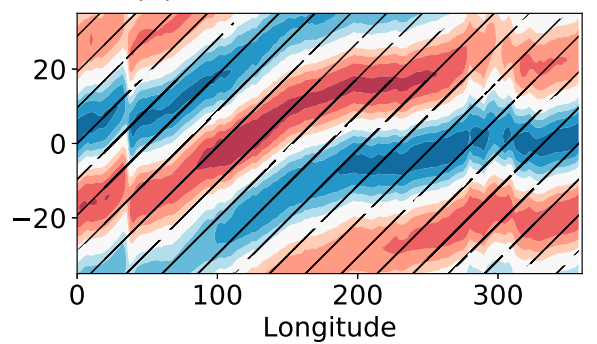

FIG. 11. Lag correlation of reconstructed (RECON) and bandpass-filtered (BP) rain anomalies based on the reference areas $\left(5^{\circ}-10^{\circ} \mathrm{N}, 110^{\circ}-120^{\circ} \mathrm{E}\right.$ and $\left.5^{\circ} \mathrm{S}-5^{\circ} \mathrm{N}, 110^{\circ}-120^{\circ} \mathrm{E}\right)$.

rPII-2, which are $\left(F_{1}, F_{2}\right)$ and $\left(O_{1}, O_{2}\right)$ for forecasts and observations, respectively. The bivariate correlation skill (COR) for the MJO index is written as

$$
\mathrm{COR}=\frac{\sum_{i=1}^{N} \mathbf{F}_{i} \cdot \mathbf{o}_{i}}{\sqrt{\sum_{i=1}^{N}\left|\mathbf{F}_{i}\right|^{2}} \sqrt{\sum_{i=1}^{N}\left|\mathbf{O}_{i}\right|^{2}}},
$$

where $i$ denotes the index of the (re)forecasts, and $N$ is the total number of (re)forecasts.
Figure 13a shows the anomaly correlation skill of rPII for $N=4772$ ECMWF reforecasts for all the seasons. The model version of the ECMWF reforecast dataset spans from 14 May 2015 to 28 December 2017, and the initial time of these reforecasts range from 21 May 1998 to 28 December 2016 . The correlation skill is $\sim 0.97$ on day 0 and drops to 0.9 by day 5 and decreases afterward. The correlation skill scales linearly with forecast leads. The rate of skill reduction is 0.15 every 10 days; it drops to 0.6 by day 24 and 0.5 by day 31 . These time leads are often considered as a useful forecast skill measure. 

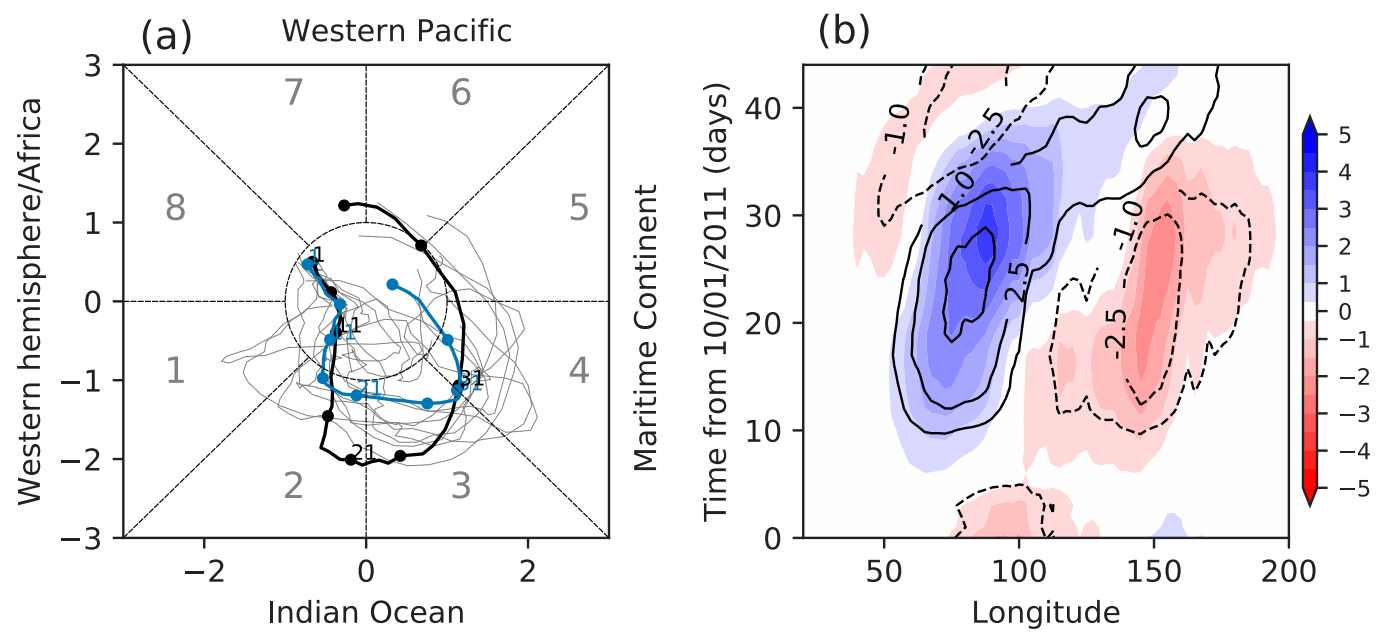

FIG. 12. (a) PII for individual ensemble members (gray), ensemble mean (blue), and observed PII (black) from the reforecasts initialized on 1 Oct 2011, from the ECMWF reforecast. (b) Predicted precipitation anomalies (shaded; $\mathrm{mm} \mathrm{day}^{-1}$ ) averaged between $10^{\circ} \mathrm{S}$ and $10^{\circ} \mathrm{N}$ for ECMWF and observed rain anomalies reconstructed from PII EOFs (contours are at $-5,-2,-1,1,2,5 \mathrm{~mm}^{-1}{ }^{-1}$; negative values are dashed).

Wang et al. (2019) also considered seasonal dependence of the forecast skill and found that the real-time OMI skill is higher in boreal winter than in summer. Similarly, we evaluate the real-time PII skill separately for the two seasons. Figure 13b shows that the rPII forecast skill is slightly higher in summer than winter, which appears to contradict the conclusion of Wang et al. (2019). A plausible explanation for this is that the MJO is more coherent from the OLR dataset, while the BSISO is more coherent in the TRMM precipitation dataset, which is caused by the decadal variability of the BSISO activities.

(a) ECMWF Forecast

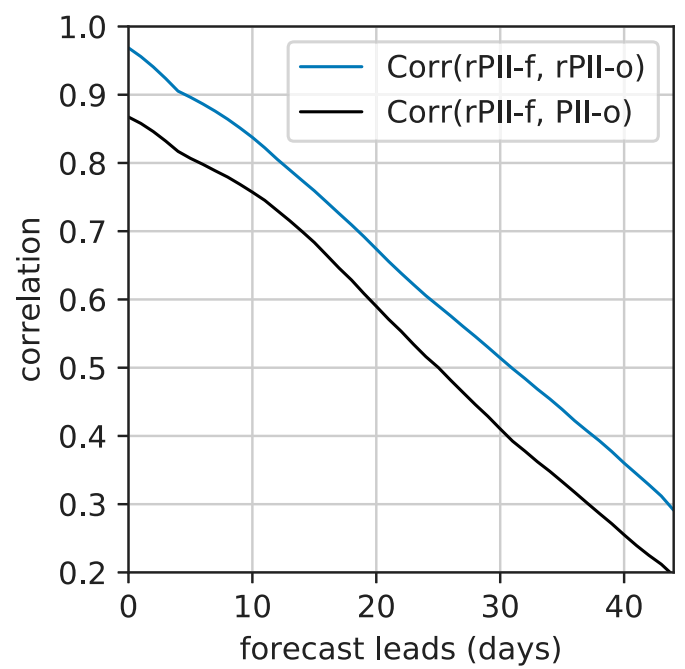

One may argue that using the approximated MJO index is overly generous to numerical models, and so we further consider a harsher measure. Instead of correlating with real-time PII for the evaluation of skill, we use observed PII for validation by using PII as $\mathbf{O}_{i}$ in Eq. (4). The black solid curve in Fig. 13a shows the rPII-PII correlation skill as a function of forecast leads. Because precipitation anomalies are computed differently in the forecasts and rPII is only an approximation of PII, the rPII-PII correlation skill drops accordingly. The correlation also scales linearly with forecast leads.

FIG. 13. (a) Anomaly correlation forecast skill of real-time PII from the EMCWF reforecasts validated using observed PII (black) and real-time PII (blue). (b) Anomaly correlation skill of real-time PII in boreal winter (December to March; blue) and summer (June to September; orange). 
It remains high during the first few days, for example, $\sim 0.88$ at day 0 , and drops to 0.6 at day 20 and 0.5 by day 25 . The PII skill is about 6 days less for all the leads compared to the correlation skill if observed rPII is used.

\section{g. Application to the diagnosis of the $M J O-Q B O$ connection}

Here we demonstrate that PII may be used to diagnose tropical intraseasonal oscillations. Several authors (Yoo and Son 2016; Son et al. 2017; Martin et al. 2019) have found that the MJO and stratosphere quasibiennial oscillation (QBO) are well correlated in the boreal winter season, and the mean amplitude of MJO during the QBO easterly phases (using the wind at $50 \mathrm{hPa}$ as the QBO index) is significantly larger than its westerly phase. However, Zhang and Zhang (2018, their Fig. 1) showed that the amplitude difference is indistinguishable in the individual $\mathrm{MJO}$ phases if the RMM is used to quantify the MJO. Here, the MJO-QBO relationship is used as an example to demonstrate the utility of the PII index for climate diagnosis. The QBO U50 index (the zonal-mean zonal wind anomaly at $50 \mathrm{hPa}$ averaged between $10^{\circ} \mathrm{S}$ and $10^{\circ} \mathrm{N}$; available at http://www.cpc.ncep.noaa.gov/data/indices/ qbo.u50.index) is used to quantify the QBO. We composite the PII index based on the 33.3rd and 66.7th percentiles of the QBO U50 index: the QBO easterly phase (QBOE) is defined if U50 is less than $-2.37 \mathrm{~m} \mathrm{~s}^{-1}$; the QBO westerly phase (QBOW) for $\mathrm{U} 50 \leq 5.13 \mathrm{~m} \mathrm{~s}^{-1}$. The MJO events are selected for the amplitude of PII greater than 0.5 . The composite results discussed below are not sensitive to these threshold values.

Figure 14 shows the phase diagram of daily PII values upon the QBOE and QBOW from December to March from 1998 to 2018. The mean amplitude (bold dots) every $24^{\circ}$ in the PII phase space is significantly larger in QBOE than in QBOW. The mean amplitude of PII is $\sim 1.31$ in QBOE and $\sim 1.18$ in QBOW. This example demonstrates that the QBO exerts significant influence on the MJO precipitation in the individual MJO phases during the TRMM period.

\section{Conclusions}

Precipitation is the most impactful variable of tropical intraseasonal variability, including both the MJO and BSISO. Here, EOF analysis is applied to precipitation anomalies associated with the MJO/BSISO using 17 years of TRMM high-quality precipitation product. The EOFs are computed as a function of the day of the year using eastward-propagating precipitation anomalies. This approach broadly follows K14 with two improvements: 1) a super-Gaussian function is used to reduce noise, and 2)

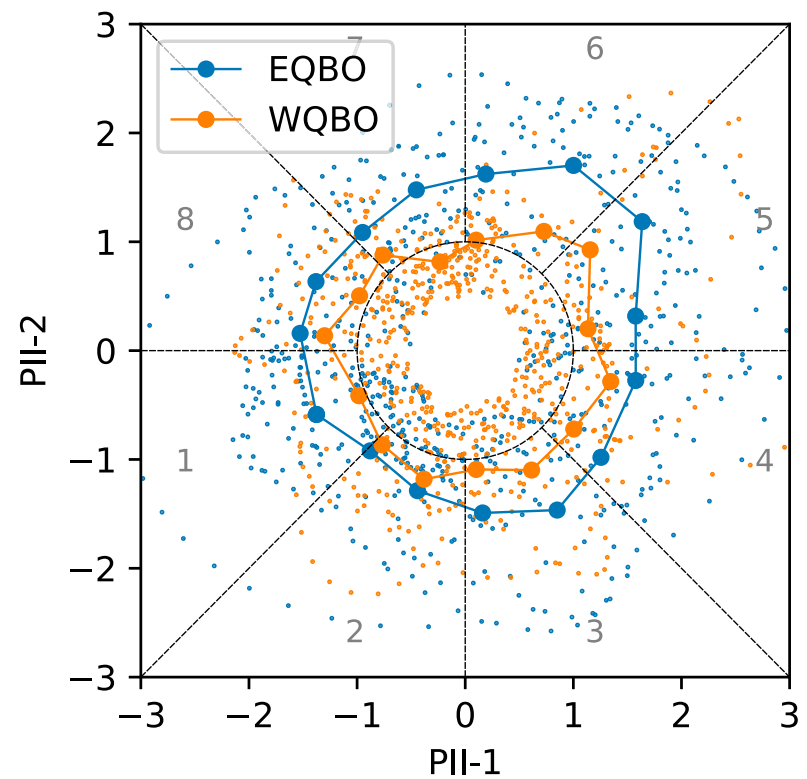

FIG. 14. The daily PII values in the EQBO (blue) and WQBO (orange) from December to March during 1998-2014. Bold dots indicate the mean of PII every $24^{\circ}$.

rotation is applied to the leading EOF pairs, which allows consistent and interpretable spatial structures across all days of the year. These developments establish a robust method to extract propagating signals from the noisy precipitation data.

Our EOF analysis identifies two peaks across the year: one in the middle of the boreal winter that explains $\sim 21 \%$ of the total variance by the first two EOFs, corresponding to the $\mathrm{MJO}$, and the other in the middle of summer that explains $20 \%$ of the total variance and corresponds to the BSISO. This result indicates that, during the TRMM period, the BSISO is more coherent than the MJO. Similar tests were repeated with OLR, which has a much longer record. It is further shown that the BSISO is much less coherent before the TRMM period (1979-98), while the MJO shows much less decadal variability. Results from the EOF analysis of OLR confirm the conclusion from the EOF analysis of precipitation.

The precipitation-based tropical intraseasonal oscillation (PII) index is developed by projecting bandpassfiltered precipitation anomalies to the rotated two leading EOFs. A real-time version that approximates PII was also developed using precipitation anomalies without any bandpass filtering. The correlation between the two is $\sim 0.9$. Applying PII and rPII to the MJO events observed from October to December 2011 during the DYNAMO field campaign shows that these precipitation indices are able to capture precipitation anomalies of these MJO events. The real-time PII is 
(a) Explained Variance

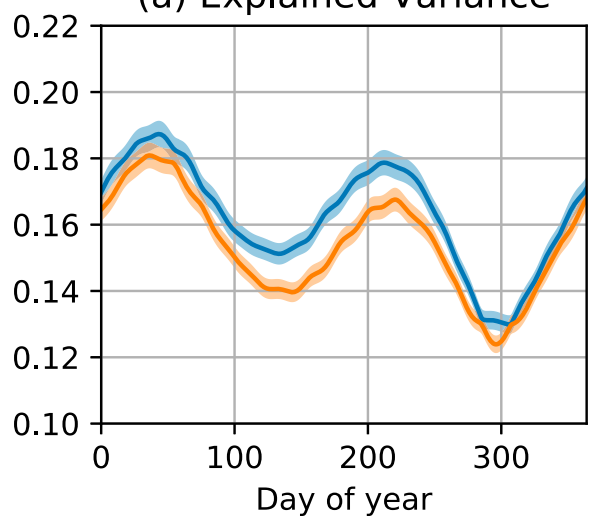

(b) Boxcar EOF1

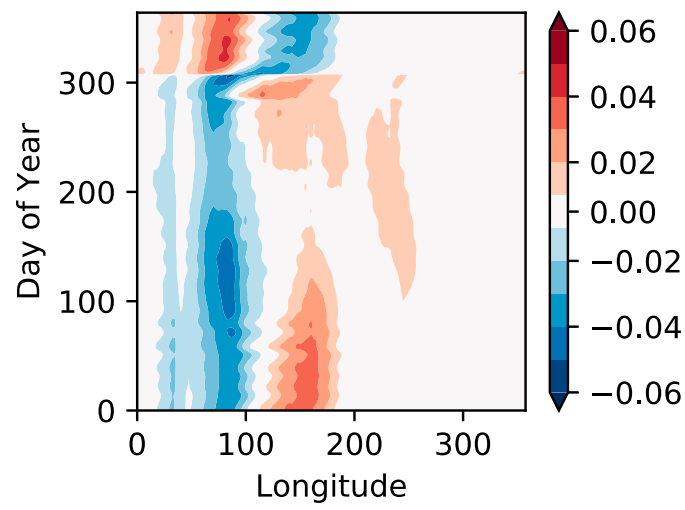

(c) Boxcar EOF2

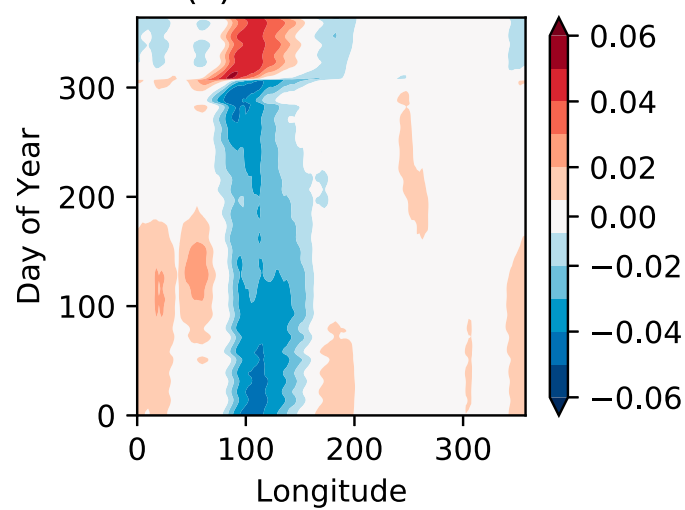

(d) Explained Variance

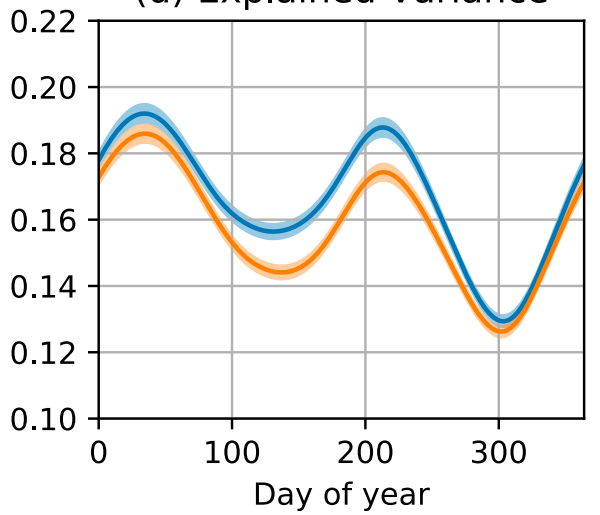

(e) Gaussian EOF1

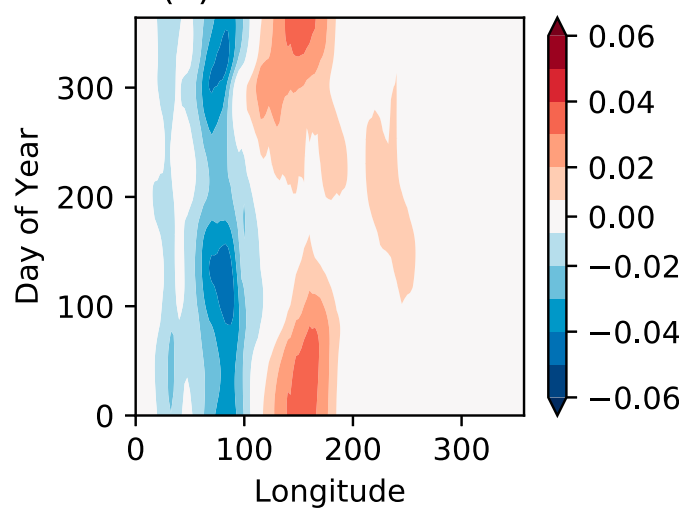

(f) Gaussian EOF2

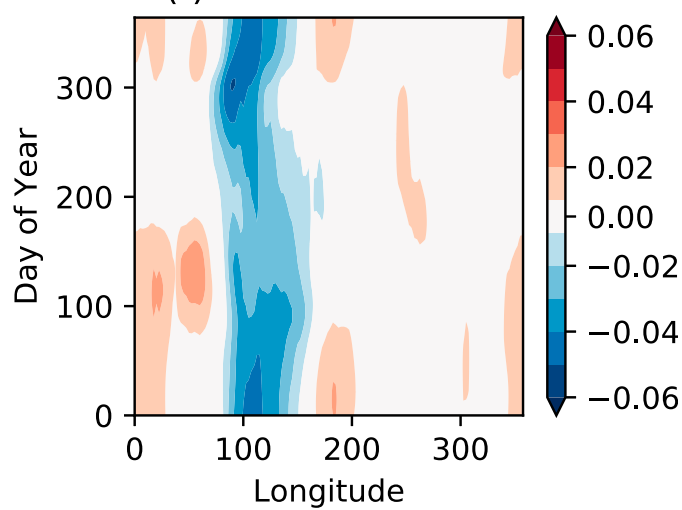

FIG. A1. (a) Explained variances following the K14 approach to generate EOFs using a boxcar window. (b),(c) Latitudinal averages of EOF1 and EOF2, respectively. (d)-(f) As in (a)-(c), but for results with a super-Gaussian window. Shading in (a) and (d) indicates the uncertainty by North's test.

used to evaluate the ECMWF reforecast of precipitation associated with the MJO and BSISO from 1998 to 2016. The forecast skill measured by the maximum lead time at which the anomaly correlation coefficient between forecasts and observations exceeds 0.6 is $\sim 24$ days, or $\sim 31$ days if a 0.5 threshold is used. The forecast skill validated with PII is $\sim 6$ days less than that derived from its real-time PII. The forecast skills between the winter and summer seasons in the forecast period are not significantly different, indicating a similar prediction skill of the $\mathrm{MJO} / \mathrm{BSISO}$ rain during the analysis period (1996-2016).

Acknowledgments. SW acknowledges support from NSF AGS-1543932 and NSFC 41875066. This research has been conducted as part of the NOAA MAPP S2S 
(a) Explained Variance

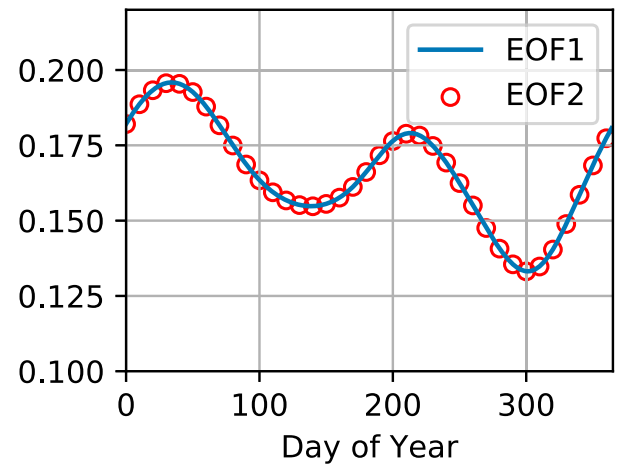

(b) EOF1, sym

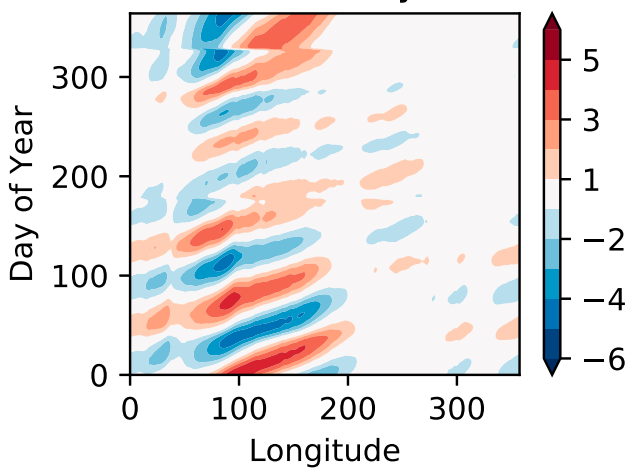

(d) rotated EOF1, sym

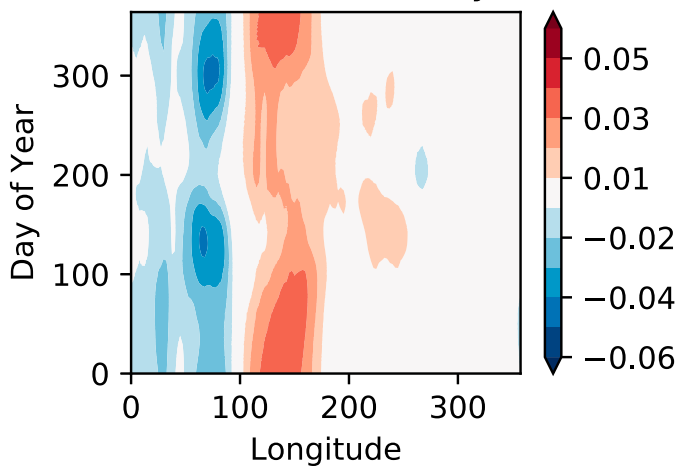

(c) EOF2, sym

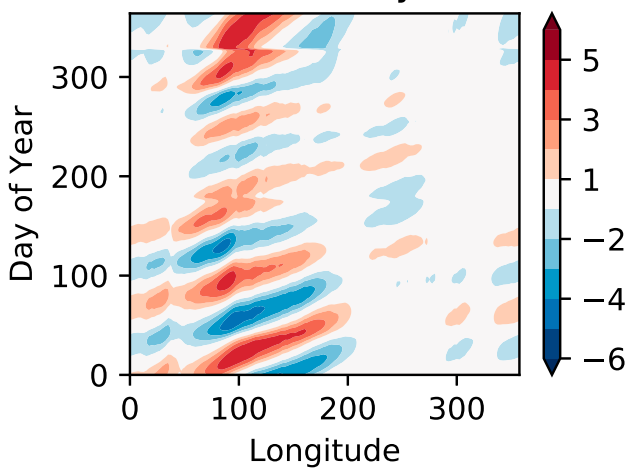

(e) rotated EOF2, sym

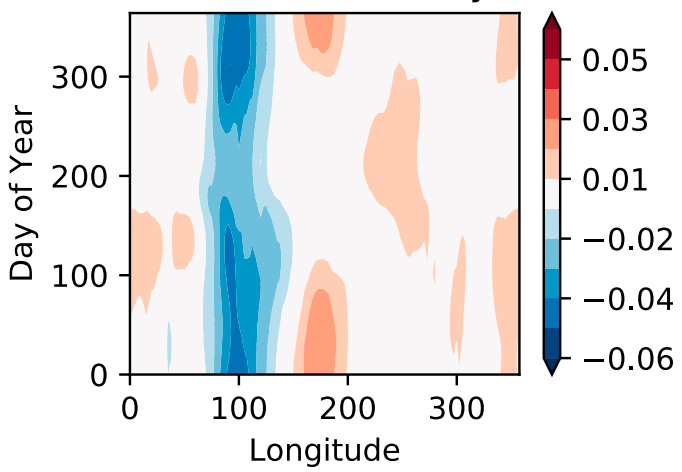

FIG. A2. OLR EOF1 and EOF2 without the zonal mean. (a) Explained variance of the first two EOFs. (b),(c) The symmetric structures of EOF 1 and 2, respectively. (d),(e) The symmetric structures of rotated EOF1 and EOF2, respectively.

Prediction Task Force and supported by NOAA Grant NA16OAR4310076. SW is grateful for discussions with Drs. Adam H. Sobel, Michael K. Tippett, and Juliana Dias. Also, SW is grateful to Dr. George N. Kiladis and an anonymous reviewer for the insightful comments. This work is supported by high-performance computing from Cheyenne (ark:/ 85065/d7wd3xhc) provided by NCAR's Computational and Information Systems Laboratory, sponsored by the National Science Foundation. The PII index is available at https://github.com/wangsg2526/PII_data and from the corresponding author.

\section{APPENDIX}

\section{Test of OLR-based MJO Index}

\section{a. Improve OMI with a super-Gaussian window}

The OMI developed by K14 is based on the interpolated OLR dataset (Liebmann and Smith 1996). OMI has many advantages as discussed in the introduction. One unsatisfying aspect of OMI is the noisiness in the EOFs. Figure A1a shows that the explained variances are not smooth, which is similar to K14's Fig. 1. 
Figures A1b and A1c illustrate the structure of the symmetric components of EOF1 and EOF2 (averaged between $20^{\circ} \mathrm{S}$ and $20^{\circ} \mathrm{N}$ ) computed following K14. The symmetric components of these EOFs are not smooth either. There is an abrupt change of sign around DOY 305-310 and 0. To avoid this abrupt transition, K14 offers a practical solution. K14 switched the sign after the abrupt transition and linearly interpolated them during the transition DOY to replace the EOFs at the transition DOY derived from the EOF analysis. As a result of linear interpolation, these EOFs maintain a consistent sign at all DOY, making them interpretable in the phase space that can be unambiguously linked to geographical regions. One weakness of this interpolation procedure is that the interpolated EOFs are not strictly orthonormal: the EOF1 and EOF2 are not strictly orthogonal, and the matrix norm of each EOF on those days is not exactly 1, albeit the relative error is small with the largest being $\sim 2 \%$. We further test the results by taking one year out prior to the EOF analysis, and repeat the same EOF analysis with one year less data. Noise and the abrupt transition vary in these tests, indicating that these features are not robust. In addition to the abrupt transition issue, the explained variance of the first two EOFs (Fig. 1b) as a function of DOY using the boxcar function as Fig. 1 in K14 is not smooth. The noisiness and abrupt transition is conceptually unsatisfying and it is desirable to have EOFs representing seasonal transition smoothly.

Applying super-Gaussian windowing with $W=60$ days to the time series data prior to EOF yields explained variances as a smooth function of DOY (Fig. A1d), which are also inseparable for half of the DOY. The symmetric and antisymmetric structure of EOFs (Figs. A1e,f) are also considerably smoother. While the EOF patterns differ slightly because of smoothing after applying the super-Gaussian window, applying these EOFs to forecast data following Wang et al. (2019) indicates negligible changes in the forecast skill, suggesting that the noise does not compromise its application in forecasts. We conclude that application of the super-Gaussian window addresses these conceptual issues in OMI. However, in practice, the original OMI is sufficient despite the numerical imprecision discussed above.

\section{b. OMI without the zonal mean}

The OLR anomalies used for OMI include the zonal mean component. We further take out the zonal mean and repeat the local EOF analysis of OLR with the super-Gaussian function, as done with precipitation anomalies. Figure A2a shows the explained variances of EOF1 and EOF2, which are identical and well separated from the other modes. The symmetric structures of EOF1 and EOF2 (Figs. A2b,d) vary rapidly because of eigenvalue degeneracy, making it difficult to interpret. We perform rotation to the first EOF pair for each DOY based on the property of eigenvalue degeneracy. After rotation, the symmetric structures of EOF1 and EOF2 (Figs. A2b,d) show consistent patterns in the Indian Ocean, western Pacific, and Maritime Continent regions, making it appropriate for indexing the convection associated with ISO.

\section{REFERENCES}

Ding, R., J. Li, and K. Seo, 2010: Predictability of the Madden-Julian oscillation estimated using observational data. Mon. Wea. Rev., 138, 1004-1013, https://doi.org/10.1175/2009MWR3082.1.

Hendon, H. H., and M. L. Salby, 1994: The life cycle of the MaddenJulian oscillation. J. Atmos. Sci., 51, 2225-2237, https://doi.org/ 10.1175/1520-0469(1994)051<2225:TLCOTM > 2.0.CO;2.

Huffman, G. J., and D. T. Bolvin, 2013: TRMM and other data precipitation data set documentation. NASA Global Change Master Directory, 40 pp., https://pmm.nasa.gov/sites/default/files/ document_files/3B42_3B43_doc_V7.pdf.

- and Coauthors, 2007: The TRMM Multisatellite Precipitation Analysis (TMPA): Quasi-global, multiyear, combined-sensor precipitation estimates at fine scales. J. Hydrometeor., 8, 38-55, https://doi.org/10.1175/JHM560.1.

Jolliffe, I. T., 1995: Rotation of principal components: Choice of normalization constraints. J. Appl. Stat., 22, 29-35, https:// doi.org/10.1080/757584395.

Kerns, B. W., and S. S. Chen, 2016: Large-scale precipitation tracking and the MJO over the Maritime Continent and IndoPacific warm pool. J. Geophys. Res. Atmos., 121, 8755-8776, https://doi.org/10.1002/2015JD024661.

Kikuchi, K., B. Wang, and Y. Kajikawa, 2012: Bimodal representation of the tropical intraseasonal oscillation. Climate Dyn., 38, 1989-2000, https://doi.org/10.1007/s00382-011-1159-1.

Kiladis, G. N., J. Dias, K .H. Straub, M. C. Wheeler, S. N. Tulich, K. Kikuchi, K. M. Weickmann, and M. J. Ventrice, 2014: A comparison of OLR and circulation-based indices for tracking the MJO. Mon. Wea. Rev., 142, 1697-1715, https://doi.org/ 10.1175/MWR-D-13-00301.1.

Krishnamurti, T. N. and D. Subrahmanyam, 1982: The 30-50 day mode at $850 \mathrm{mb}$ during MONEX. J. Atmos. Sci., 39, 20882095, https://doi.org/10.1175/1520-0469(1982)039<2088: TDMAMD $>2.0 . C O ; 2$.

Li, T., L. Wang, M. Peng, B. Wang, C. Zhang, W. Lau, and H. Kuo, 2018: A paper on the tropical intraseasonal oscillation published in 1963 in a Chinese journal. Bull. Amer. Meteor. Soc., 99, 1765-1779, https://doi.org/10.1175/BAMSD-17-0216.1.

Liebmann, B., and C. A. Smith, 1996: Description of a complete (interpolated) outgoing long-wave radiation dataset. Bull. Amer. Meteor. Soc., 77, 1275-1277, https://www.jstor.org/ stable/26233278.

Lin, H., G. Brunet, and J. Derome, 2008: Forecast skill of the Madden-Julian oscillation in two Canadian atmospheric models. Mon. Wea. Rev., 136, 4130-4149, https://doi.org/ 10.1175/2008MWR2459.1.

Liu, P., Q. Zhang, C. Zhang, Y. Zhu, M. Khairoutdinov, H. Kim, C. Schumacher, and M. Zhang, 2016: A revised Real-Time Multivariate MJO index. Mon. Wea. Rev., 144, 627-642, https://doi.org/10.1175/MWR-D-15-0237.1. 
Madden, R. A., and P. R. Julian, 1971: Detection of a 40-50 day oscillation in the zonal wind in the tropical Pacific. J. Atmos. Sci., 28, 702-708, https://doi.org/10.1175/1520-0469(1971)028<0702: DOADOI $>2.0 . \mathrm{CO} ; 2$.

__, and —_, 1972: Description of global-scale circulation cells in the tropics with a 40-50 day period. J. Atmos. Sci., 29, 1109-1123, https://doi.org/10.1175/1520-0469(1972)029<1109: DOGSCC $>2.0 . \mathrm{CO} ; 2$.

Maloney, E. D., and D. L. Hartmann, 1998: Frictional moisture convergence in a composite lifecycle of the Madden-Julian oscillation. J. Climate, 11, 2387-2403, https://doi.org/10.1175/ 1520-0442(1998)011<2387:FMCIAC $>2.0$.CO;2.

Martin, Z., S. Wang, J. Nie, and A. Sobel, 2019: The impact of the QBO on MJO convection in cloud-resolving simulations. J. Atmos. Sci., 76, 669-688, https://doi.org/10.1175/JAS-D-18-0179.1.

North, G. R., T. L. Bell, R. F. Cahalan, and F. J. Moeng, 1982: Sampling errors in the estimation of empirical orthogonal functions. Mon. Wea. Rev., 110, 699-706, https://doi.org/ 10.1175/1520-0493(1982)110<0699:SEITEO > 2.0.CO;2.

Richman, M. B., 1986: Rotation of principal components. J. Climatol., 6, 293-335, https://doi.org/10.1002/joc.3370060305.

Roundy, P. E., C. J. Schreck, and M. A. Janiga, 2009: Contributions of convectively coupled equatorial Rossby waves and Kelvin waves to the real-time multivariate MJO indices. Mon. Wea. Rev., 137, 469-478, https://doi.org/10.1175/ 2008MWR2595.1.

Sobel, A. H., E. D. Maloney, G. Bellon, and D. M. Frierson, 2010: Surface fluxes and tropical intraseasonal variability: A reassessment. J. Adv. Model. Earth Syst., 2 (2), https://doi.org/ 10.3894/JAMES.2010.2.2

- S. Wang, and D. Kim, 2014: Moist static energy budget of the MJO during DYNAMO. J. Atmos. Sci., 71, 4276-4291, https:// doi.org/10.1175/JAS-D-14-0052.1.

Son, S.-W., Y. Lim, C. Yoo, H. H. Hendon, and J. Kim, 2017: Stratospheric control of Madden-Julian oscillation. J. Climate, 30, 1909-1922, https://doi.org/10.1175/JCLI-D-16-0620.1.

Straub, K. H., 2013: MJO initiation in the real-time multivariate MJO index. J. Climate, 26, 1130-1151, https://doi.org/10.1175/ JCLI-D-12-00074.1.

Ventrice, M. J., M. C. Wheeler, H. H. Hendon, C. J. Schreck, C. D. Thorncroft, and G. N. Kiladis, 2013: A modified multivariate Madden-Julian oscillation index using velocity potential. Mon. Wea. Rev., 141, 4197-4210, https://doi.org/ 10.1175/MWR-D-12-00327.1.

Vitart, F., and Coauthors, 2017: The Subseasonal to Seasonal (S2S) prediction project database. Bull. Amer. Meteor. Soc., 98, 163 173, https://doi.org/10.1175/BAMS-D-16-0017.1.
Waliser, D., and Coauthors, 2009: MJO simulation diagnostics. J. Climate, 22, 3006-3030, https://doi.org/10.1175/2008JCLI2731.1.

Wang, S., A. H. Sobel, F. Zhang, Q. Sun, Y. Yue, and L. Zhou, 2015: Regional simulation of the October and November MJO events observed during the CINDY/DYNAMO field campaign at gray zone resolution. J. Climate, 28, 2097-2119, https://doi.org/10.1175/JCLI-D-14-00294.1.

_ - _ , and J. Nie, 2016: Modeling the MJO in a cloudresolving model with parameterized large-scale dynamics: Vertical structure, radiation, and horizontal advection of dry air. J. Adv. Model. Earth Syst., 8 (1), 121-139, https://doi.org/ 10.1002/2015MS000529.

—, D. Ma, A. H. Sobel, and M. K. Tippett, 2018: Propagation characteristics of BSISO indices. Geophys. Res. Lett., 45, 9934-9943, https://doi.org/10.1029/2018GL078321.

_ , and A. H. Sobel, M. K. Tippett, and F. Vitart, 2019: Prediction and predictability of tropical intraseasonal convection: Seasonal dependence and the Maritime Continent prediction barrier. Climate Dyn., 52, 6015-6031, https://doi.org/10.1007/ s00382-018-4492-9.

Wheeler, M. C., and H. H. Hendon, 2004: An all-season real-time multivariate MJO index: Development of an index for monitoring and prediction. Mon. Wea. Rev., 132, 1917-1932, https:// doi.org/10.1175/1520-0493(2004)132<1917:AARMMI>2.0.CO;2.

Xie, Y. B., S. J. Chen, I. L. Zhang, and Y. L. Hung, 1963: A preliminarily statistic and synoptic study about the basic currents over southeastern Asia and the initiation of typhoon. Acta Meteor. Sin., 33, 206-217.

Yasunari, T., 1979: Cloudiness fluctuations associated with the northern hemisphere summer monsoon. J. Meteor. Soc. Japan, 57, 227-242, https://doi.org/10.2151/jmsj1965.57.3_227.

Yoneyama, K., C. Zhang, and C.N. Long, 2013: Tracking pulses of the Madden-Julian oscillation. Bull. Amer. Meteor. Soc., 94, 1871-1891, https://doi.org/10.1175/BAMS-D-12-00157.1.

Yoo, C., and S.-W. Son, 2016: Modulation of the boreal wintertime Madden-Julian oscillation by the stratospheric quasi-biennial oscillation. Geophys. Res. Lett., 43, 1392-1398, https://doi.org/ 10.1002/2016GL067762.

Zhang, C., 2013: Madden-Julian oscillation: Bridging weather and climate. Bull. Amer. Meteor. Soc., 94, 1849-1870, https:// doi.org/10.1175/BAMS-D-12-00026.1.

— , and J. Ling, 2017: Barrier effect of the Indo-Pacific Maritime Continent on the MJO: Perspectives from tracking MJO precipitation. J. Climate, 30, 3439-3459, https://doi.org/10.1175/ JCLI-D-16-0614.1. , and B. Zhang, 2018: QBO-MJO connection. J. Geophys. Res. Atmos., 123, 2957-2967, https://doi.org/10.1002/2017JD028171. 